\title{
متطلبات تطوير مقر بناء المناهج من وجهة نظر الطلبة وأعضاء هيئة التدربس في جامعة الملك فيصل
}

\author{
مهند عبداللطيف الجعفري \\ أستاذ مساعد بقسم المناهج وطرق التدريس- جامعة الملك فيصل- السعودية \\ aljafary@kfu.edu.sa

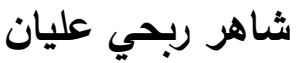 \\ أستاذ مساعد بكلية التربية والآداب- جامعة صحار - سلطنة عُمان \\ se72sc@gmail.com
}

تأتي الدراسة الحالية منسجمة مع الجهود الرامية إلى تطوير منظومة التعليم والتعلم في جامعة الملك فيصل، وهي تهدف إلى الى استقصاء الاحتياجات اللازمة لتطوير مقرر بناء المناهج الذي يدرسه الطلبة في كلية التربية. اتبعت الدراسة المنهج الوصفي والاستبانة كأداة لجمع البيانات، حيث تكونت من · ج فقرة وزعت على ثلاثة محاور : مفردات المقرر، وإجراءات تتفيذ المقرر ، ومصادر التعلم. تثكلت عينة الدراسة من (·r) عضوا من أعضاء هيئة التدريس في كلية التربية الذين يُدرسون المقرر تم اختيارهم بالطريقة القصدية، والطلبة الذين درسوا المقرر، وقد تم اختيار (01) طالبة و (V0) طالبا بالطريقة العشوائية البسيطة. أظهرت نتائج الدراسة أهمية الاحتياج إلى بعض المفردات في تدريس المقرر مثل ربط المنهج بقضايا ومشكلات المجتمع، وكنلك الاطلاع على الى

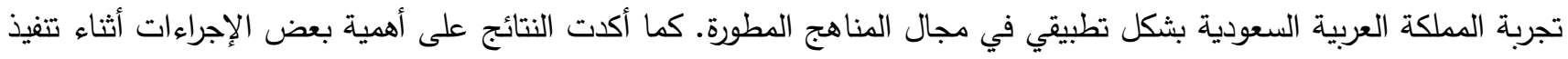
المقرر مثل: التتويع في أسئلة الاختبارات التحصيلية، ووجود العدد المناسب من الطلبة في الثعبة الواحدة، واستبعاد المذكرات والملخصات كمصادر للتعلم.

الكلمات المفتاحية: مقرر بناء وتطوير المناهج، تطوير المناهج.

\section{(c) (1)}

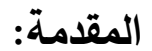

تعد مؤسسات التعليم العالي في أي دولة حاضنات معرفة، ونموذجاً يتوجب الإشارة إليه من قبل مؤسسات المجتمع الأخرى؛

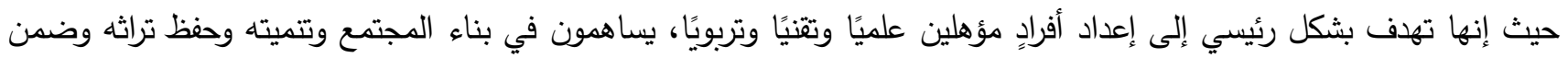

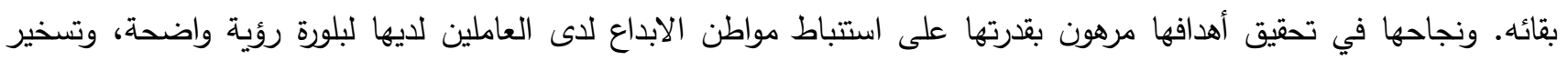
جميع الخدمات اللوجستية التي تساهم في تتمية معارفهم ومهاراتهم، وبناء برامج تلبي حاجات المتعلمين وفروقهم الفردية. 
يُشكّل البرنامج الأكاديمي الذي تقدمه مؤسسات التعليم العالي متمثلة في الجامعات منظومة متكاملة عناصرها الرئيسة هي: عضو هيئة التدريس والطالب والمنهاج الدراسي، يضاف لها بيئة (أو سياق) التعلم بما تشمله من خدمات ومرافق ومعينات للتعلم

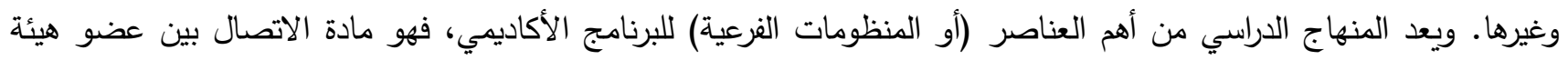

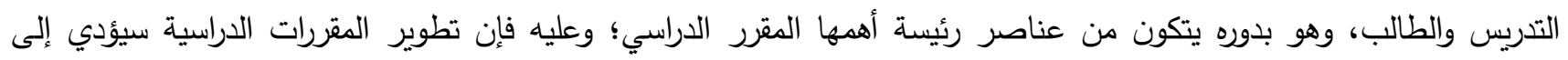

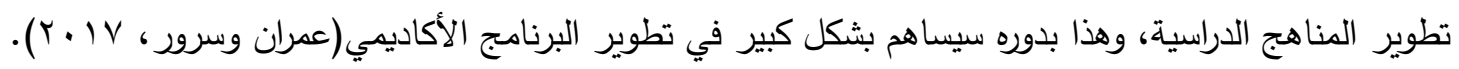

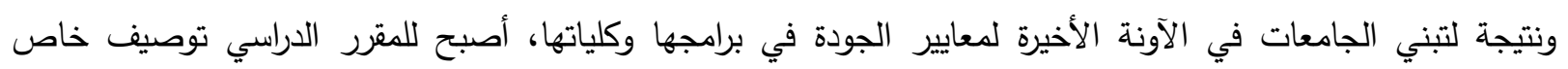
يتطلب تصميما محكما يشتمل على أهداف المقرر العامة (Course Profile)

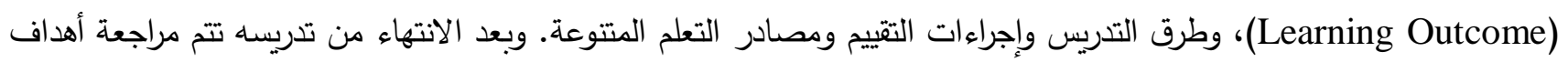
ونواتج ومحتوى المقرر وجميع إجراءاته (Course Review)، والتحقق من مدى مطابقة ذلك كله مع التوصيف، واتخاذ التدابير اللازمة في حالة وجود خلل في المطابقة مع التوصيف كله أم مع بعض عناصره، حتى لا تتكرر في الفصول الدراسية اللاحقة؛ وهذا يشير بشكل واضح إلى الاهتمام المتزايد بالمقررات الدراسية والاستمرار في تقييمها وتطويرها.

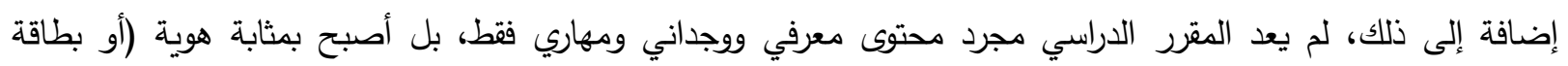

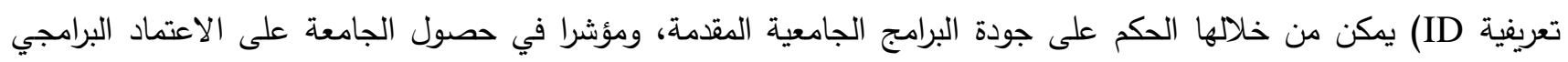
(الخاص)؛ مما دفع باتجاه استحداث هيئات على مستوى الدولة لمتابعة البرامج والمقررات الدراسية مثل الهيئة الوطنية للتقويم والاعتماد الأكاديمي في المملكة العربية السعودية، والهيئة العُمانية للاعتماد الأكاديمي، وهيئة اعتماد مؤسسات التعليم العالي وضمان جودتها في المملكة الأردنية الهاشمية، وغيرها في باقي الدول العربية ودول العالم. وقد ساهم ذلك في تحسين إجراءات وهات التدريس والتقويم والتطوير ، كما ساهم في تسهيل إجراءات معادلة المقررات، وانتقال الطالب لسبب أو لآخر من جامعة إلى أخرى في في نغس الدولة، وربما بين الدول(Forest \& Altbach, 2007). وانسجاما مع هذا الحراك الأكاديمي والمجتمي الذي يثير إلى تنامي الاهتمام بالمقررات الدراسية، تأتي الدراسة الحالية التي

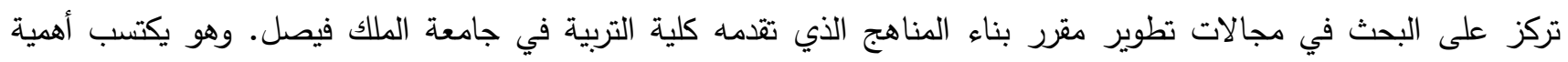
قصوى في التطوير المستمر؛ كونه مقررا رئيسا في إعداد المعلم، فهو يزود الطالب/المعلم بأسس تخطيط وبناء المناهج الدراسية

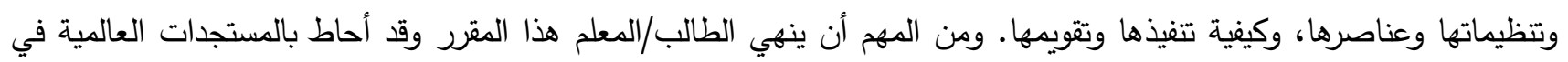
مجال المناهج، وكذلك التغيرات المحلية ذات الصلة في مدارس التعليم؛ بما يساعد في تقليص الفجوة بين مقررات إعداد المعلمين في

$$
\text { الجامعات - بشكل عام - والواقع الميداني. }
$$

\section{مشكلة الاراسة:}

يُعد مقرر بناء المناهج من المقررات التي يقدمها قسم المناهج وطرق التدريس إلى جميع الطلبة في كلية التربية بمختلف

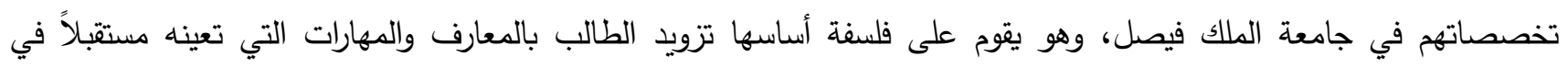
تصميم وحدة دراسية بكافة عناصرها الرئيسة والفرعية، أو تمكنه من تحليل وحدة دراسية من الكتاب المقرر أثناء عمله في الميدان كمعلم.

وقبل حوالي خمس سنوات (أي في العام rا • r )، تم وضع توصيف للمقرر وفقا لمتطلبات هيئة الاعتماد والجودة في

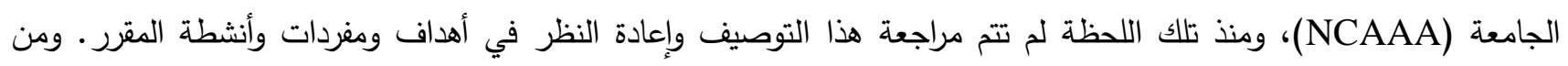

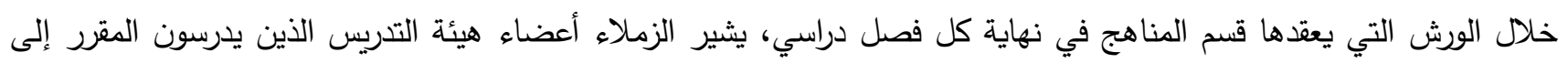

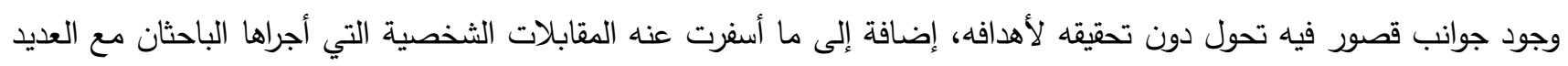

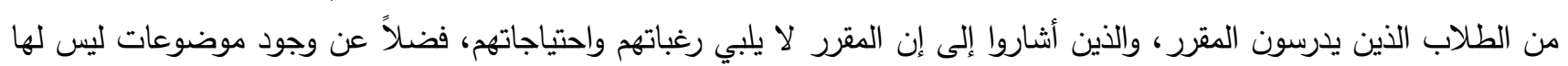


من هنا جاءت فكرة القيام بهذه الدراسة، والتي تلقي الضوء على احتياجات (متطلبات) تدريس مقرر بناء المناهج، من حيث أهمية مفرداته وإجراءات تدريسه ومصادر التعلم فيه. وبشكل رئيس ستحاول الدراسة الإجابة عن السؤال الرئيس الآتي:

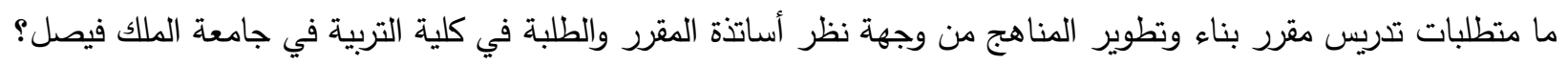

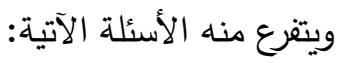
ا. ما مدى الاحتياج للمفردات المتضمنة في مقرر بناء المناهج الحالي من وجهة نظر أساتذة المقرر والطلبة في كلية التربية

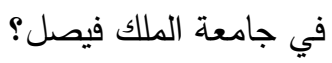
r. ما مدى الاحتياج للإجراءات التدريسية المطبقة في مقرر بناء المناهج الحالي من وجهة نظر أساتذة المقرر والطلبة في كلية التربية في جامعة الملك فيصل؟ الاحتئ لجراءت r. ما مدى الاحتياج لمصادر التعلم المستخدمة في مقرر بناء المناهج الحالي من وجهة نظر أساتذة المقرر والطلبة في كلية التربية في جامعة الملك فيصل؟ الاحتباج ع. هل يوجد فرق ذو دلالة إحصائية(عند مستوى هe=0.05) بين تكرارات استجابات الطلبة الذكور والإناث فيما يتعلق بمدى الإى

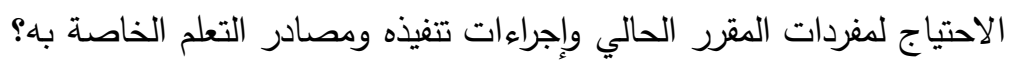

ا. الكثف عن نقاط الضعف والقوة في مقرر بناء المناهج، لتقديم وجهة النظر البديلة للموضوعات التي يقترح الباحثان تضمينها لهذه المادة التربوية، وعرض ذلك كبديل إرشادي تدريسي مقترح. r. ندرة البحوث التي أجريت في المجال، حيث تعد هذه الدراسة - ضمن حدود معرفة واطلاع الباحثين - أول دراسة تحليلية تقييمية تجرى على أحد المقررات في جامعة الملك فيصل، وربما تساهم في دفع مزيد من الزملاء في كلية التربية وكليات

$$
\text { أخرى إلى إعادة النظر في مقرراتهم وتحديثها. }
$$

r. تتسجم مع الحراك الإيجابي في جامعة الملك فيصل الذي يهدف إلى تحسين وتطوير التعليم الجامعي بكافة مدخلاته وعملياته.

\section{حدود الدراسةة:}

ستقتصر هذه الدراسة على مقرر بناء وتطوير المناهج الذي درسه الطلبة في كلية التربية جامعة الملك فيصل خلال الفصل

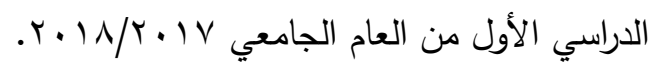

\section{مصطلحات الدراسة: \\ مقرر بناء المناهج:}

هو المقرر الذي يدرسه الطلبة في المستوى الثاني من مرحلة البكالوريوس في كلية التربية في جامعة الملك فيصل، ويعتبر

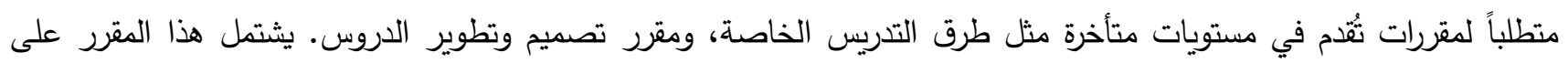
أسس بناء المناهج وعناصره وتتظيماته وعملياته.

تطوير المناهج:

هي إحدى عمليات المنهج، وهي العملية التي تلي عملية تقويم المنهج معتمدة على نتيجته. وفي هذه الدراسة فإن عملية تطوير المنهج تُقاس بمدى الاحتياج لمفردات المقرر الحالي وإجراءات تتفيذه ومصادر التعلم له، وذلك من وجهة نظر أساتذة المقرر والطلاب والطالبات الذين درسوا المقرر • بعل 
المقرر الدراسي هو جزء من المنهاج الدراسي، يشتمل على الخبرات المعرفية والوجدانية والمهارية التي يطلب من المتعلمين تعلمها في مادة من المواد خلال سنة دراسية. وهو مجموعة من الموضوعات الدراسية التي يلزم الطلبة بدراستها في فترة زمنية محددة، تتراوح بين فصل دراسي إلى عام دراسي كامل، وفق خطة محددة، ويساهم النجاح فيه وتحقيق جميع متطلباته في الحصول على درجة علمية علي (r... (r). تتتوع المقررات التي تطرحها الجامعات، حيث يمكن تصنيفها حسب موقعها في البرنامج الدراسي (أو الخطة الدراسية) إلى إلى مقررات إجبارية Core Courses، وهي متطلبات أساسية للتخرج، وتكون في جميع أقسام الخطة الدراسية كمنطلبات الجامعة

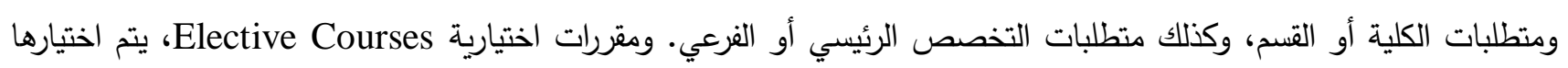

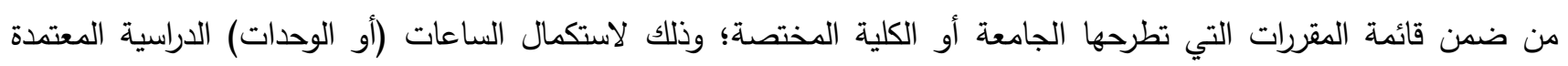

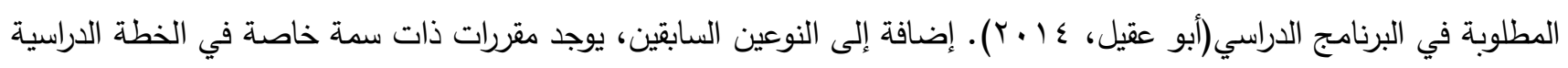
يحددها ويضع شروطها القسم المختص مثل مقررات المتطلبات السابقة Pre-requisite Courses التي يشترط النجاح فيها تمهيدا لدراسة مقررات ذات صلة تتصف بعمق أكبر في المادة العلمية، والمقررات المتزامنة Synchronous Coursesالتي يسجلها الطالب في فصل واحد مثل مقرر الفيزياء ومقرر مختبر الفيزياء. أما من حيث طريقة تقديمها للطلبة فيمكن تصنيفها إلى مقررات بالمحاضرة Lecture Course، حيث يقدم مدئرة مدرس المقرر

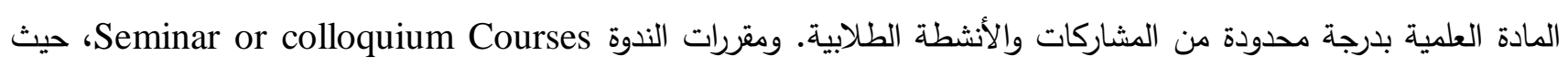
يوزع المدرس القراءات العلمية على الطلبة لتحضيرها وعرضها بشكل جماعي أو فردي من أجل المناقشة والتتييم. ومقررات الدورات

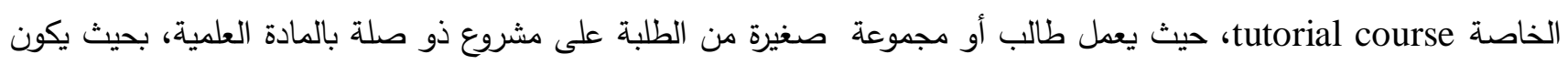

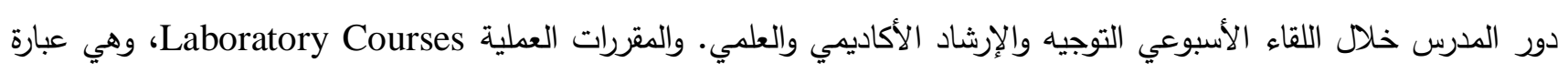

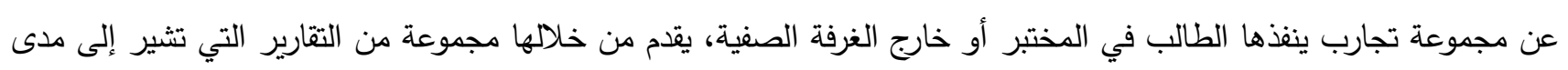

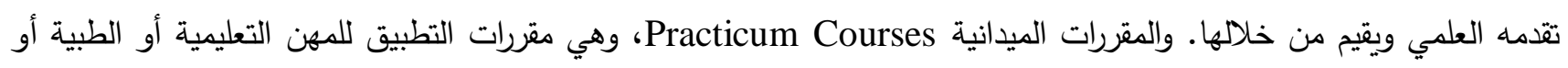
الهندسية، وتكون عادة في الفصل الأخير للدراسة، حيث يقضي الطلبة فترة المقرر في أماكن العمل مثل المدارس والمستشفيات

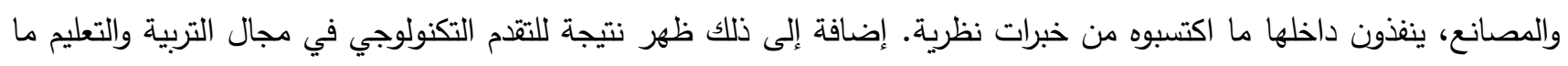
يسمى المقررات الاكترونية التي تقدم عن طريق برنامج التعلم عن بعد الذي تطرحه الجامعات، أو عن طريق المنصات التعليمية ومن أشهرها MOOC-Massive Open Online Course يؤدي الاهتمام بتقييم المقررات الدراسية إلى تطويرها وتحديثها بشكل مستمر بما يحقق متطلبات الثورة المعرفية الثاملة التي يشهاها عصرنا الحالي، ويمكن تعريف عملية تقييم المقرر الدراسي على أنها عملية منهجية مخططة ومنظمة تهدف إلى إلى تقديم تشخيص لجوانب القوة والضعف للمقرر، عن طريق أدوات القياس التي تم إعدادها وفق منهجية علمية، ومن ثم إصدار الحكم واتخاذ

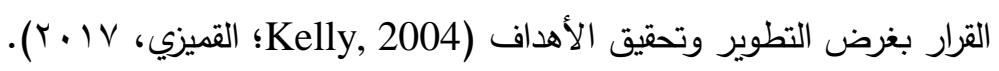
تشير الدراسات (Tanner \& Tanner, 2007; Wiles, 2009) إلى أن عملية تقييم وتطوير المقررات الدراسية تمر بعدة مراحل مترابطة متكاملة هي: تصنير الراست

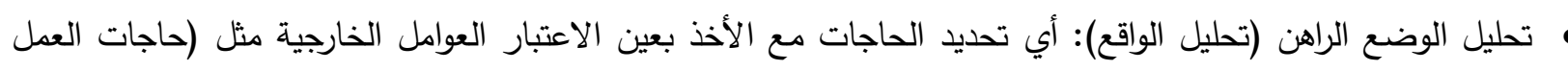

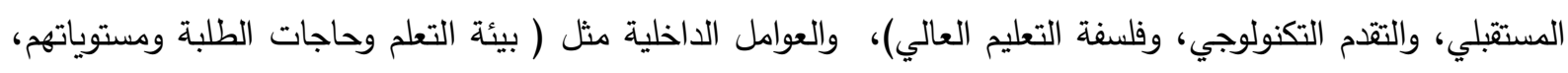
والكفاءات المنوطة بالمقرر ، وعناصر المقرر أو جزء من تلك العناصر ). • تحليل الأهداف: حيث يتم في هذه المرحلة تحديد الهدف من عملية التقييم وهو معرفة واقع المقرر، ومعرفة نقاط القوة

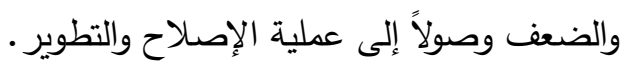




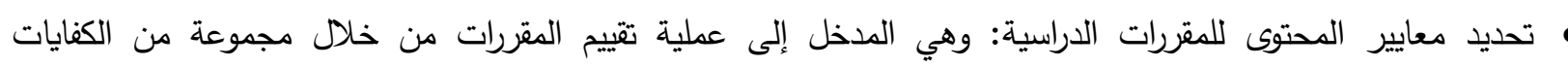
والمحكات مثل: الاعتماد الأكاديمي والجودة الثاملة.

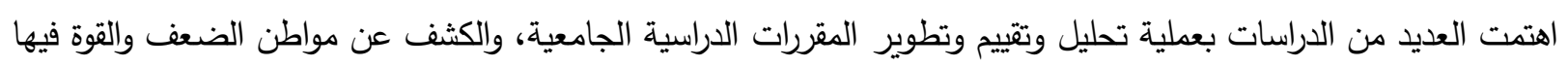

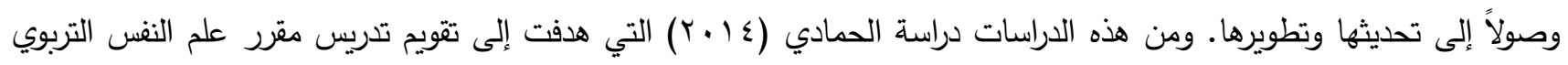

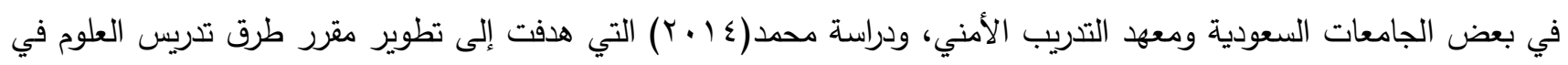

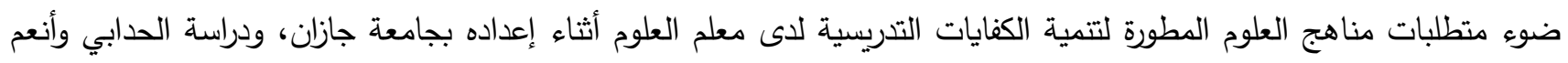

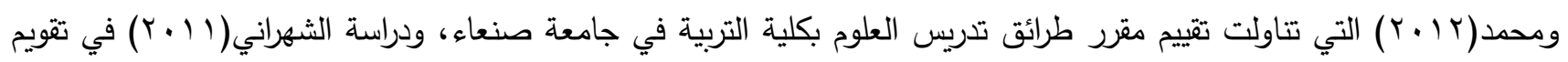

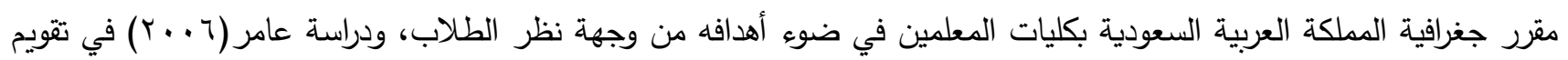

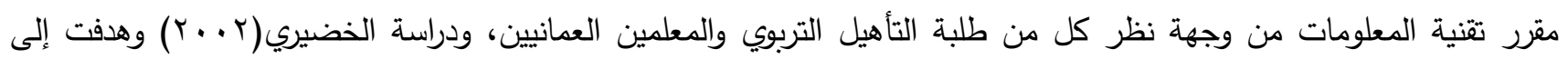
تقويم مقرر أدب الأطفال في أقسام اللغة العربية بكليات المعلمين. بالرغم من اشتمال الأدب التربوي على الكثير من الدراسات في مجال تقييم وتطوير المناهج و المقررات، إلا أنه تم اختيار

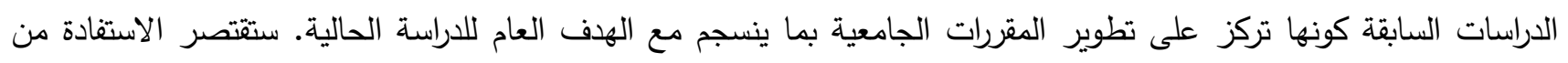
الدراسات السابقة في بناء أداة الدراسة وإجراءات تطبيقها، في حين أنه يصعب مقارنة نتائج الدراسة الحالية مع نتائج الدراسات السابقة، كون المقرر الذي ستتم دراسته مختلف في أهدافه ومحتواه وإجراءات تقييمه وتطويرهعن المقررات في الدراسات السابقة.

\section{إجراءات الدراسة:}

مجتمع الاراسة:

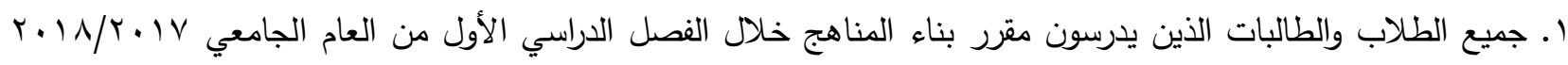
في كلية التربية في جامعة الملك فيصل. r. جميع أعضاء هيئة التدريس الذكور والإناث الذين يقدمون مقرر بناء المناهج خلال الفصل الدراسي الأول من العام الجامعي

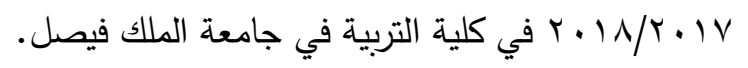

\section{عينة الاراسة:}

تثكلت عينة الدراسة من (•r) عضواً من أعضاء هيئة التدريس (الذكور والإناث) الذين درسوا مقرر بناء المناهج خلال

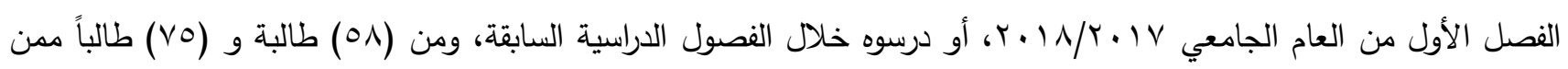

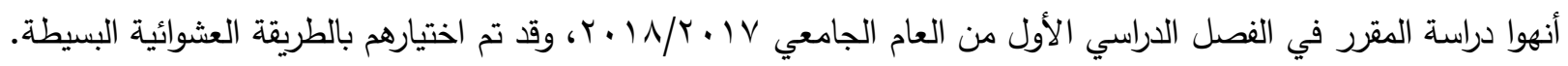
أداة الدراسة

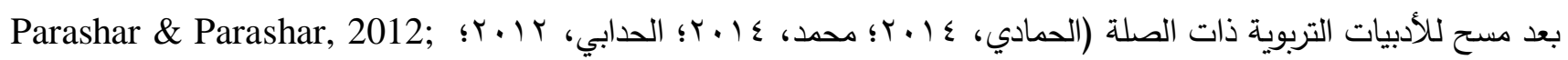
تم بناء الاستبانة كأداة للدراسة، حيث تكونت من ثلاثة محاور : المحور الاول

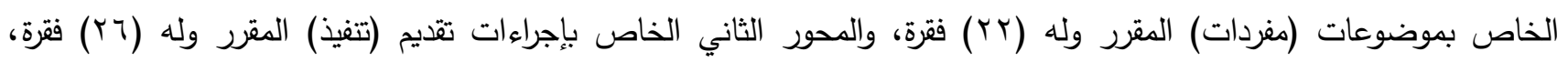
والمحور الثالث الخاص بمصادر التعلم وله (Y) فقرة. وقد تم بناء الاستبانة على هيئة مقياس ليكرت الخماسي، بحيث يختار

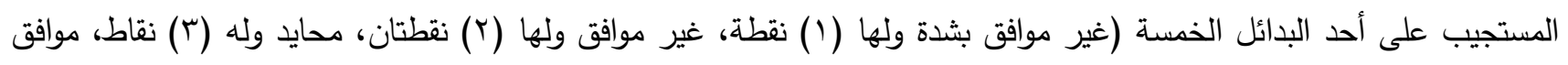
ولها (ع) نقاط، موافق بشدة ولها (0) نقاط).

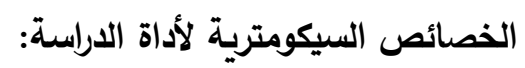
1 أصدق الظاهري

تم عرض الاستبانة في صورتها الأولية على السادة المحكمين وعددهم (^) من المتخصصين في مجال المناهج وتطويرها ممن يعملون خارج جامعة الملك فيصل؛ وفي ضوء وجهات نظر المحكمين، تم إعادة صياغة بعض الفقرات، وإعادة ترتيب بعضها 
الآخر ـ كما تم احتساب النسب المئوية للاتفاق بين السادة المحكمين على فقرات الاستبانة باستخدام معادلة كوبر ، وهي موضحة في

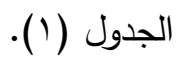

الجدول (1): المتوسط الحسابي للنسب المئوية لاتفاق السادة المحكمين على فقرات الاستبانة

\begin{tabular}{|c|c|}
\hline المتوسط الحسابي & فقرات المحور \\
\hline$\% \wedge \uparrow, \varepsilon$ & الأول \\
\hline$\% q r, r$ & الثاني \\
\hline$\% 91,7$ & الثالث \\
\hline
\end{tabular}

يتضح من الجدول (1) أن النسب المئوية لاتفاق السادة المحكمين على فقرات محاور الاستبانة جاءت مرتفعة. ومن خلال ما يثير إليه الأدب التربوي بأن نسبة مئوية لاتفاق المحكمين أعلى من •^^\% تعني قبول المحكمين للأداة (الاستبانة)، وموافقتهم

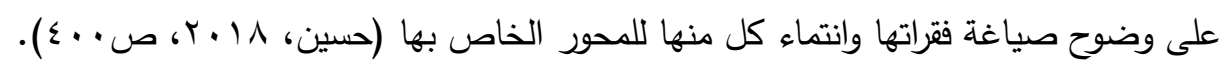

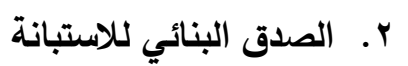

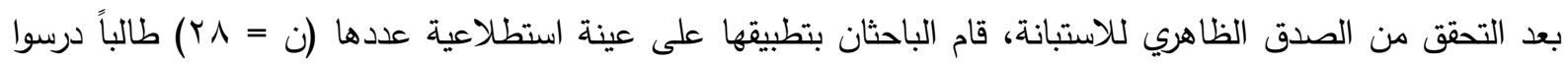

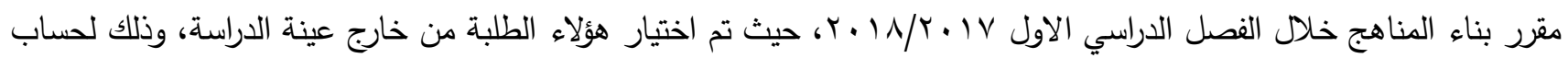

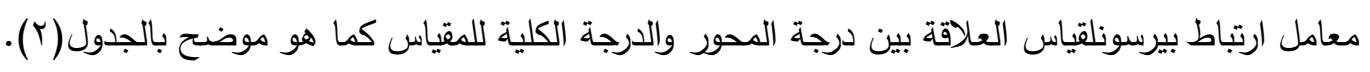
الجدول(ץ): معامل ارتباط بيرسون بين محاور الاستبانة و الارجة الكلية

\begin{tabular}{|c|c|c|}
\hline معامل الارتباط & عنوان المحور & المحور - - الم \\
\hline$* *, \wedge \mathrm{Y}$ & الدفردات المتضمنة في مقرر بناء المناهج & 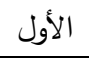 \\
\hline$* *, 9$ & إجراءات التتفيذ & الثاني \\
\hline$* *, \wedge T$ & مصادر التعلم & 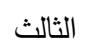 \\
\hline
\end{tabular}

"* دالة إحصائيا عند مستوى الدلالة ا ., .

يشير الجدول (Y) أن جميع معاملات ارتباط المحاور بالدرجة الكلية مرتفعة نسبيا، ودالة إحصائياً عند مستوى الدلالة

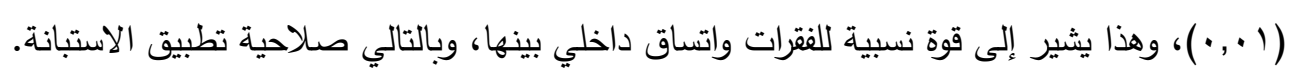

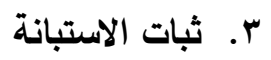

قام الباحثان بتطبيق الاستبانة على عينة استطلاعية (من خارج عينة الدراسة) عدد أفرادها (ن = ب ب)؛ لحساب الثبات

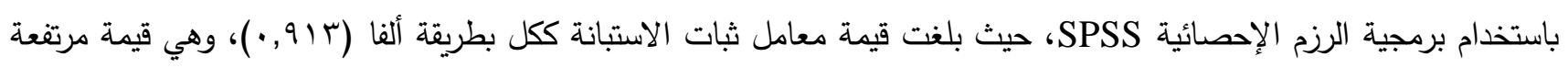
نسبياً تجعل من الأداة صالحة للتطبيق.

\section{عرض نتائجج الاراسة وتفسيراتها:}

بعد التحقق من الخصائص السيكومترية لأداة الدراسة، تم تطبيقها على عينة الدراسة من أساتذة المقرر والطلاب والطالبات، وجمع البيانات الأولية، ومن ثم احتساب المتوسطات الحسابية والانحرافات المعيارية ومدى الاحتياج لكل فقرة من فقرات

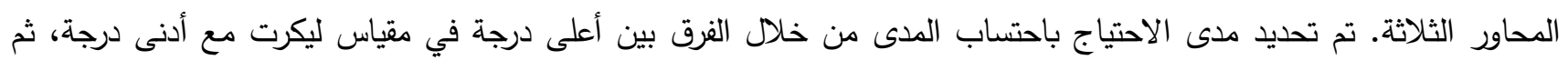
قسمة الفرق المطلق على أعلى درجة في مقياس ليكرت، وبالتالي تحدد مدى الاحتياج حسب ما يظهر في الجدول (r). 
الجدول (ץ): تحديد مدى الاحتياج لفقرات الاستبانة

\begin{tabular}{|c|c|}
\hline المدى الاحتياج & الفترة الفت \\
\hline ضعيف جدا & من · 1, - - 1, 1 \\
\hline ضعيف & أكبر من •^, 1 - • r, r \\
\hline متوسط & 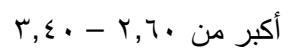 \\
\hline 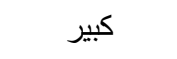 & أكبر من • • \\
\hline كبير جدا & أكبر من • • \\
\hline
\end{tabular}

الإجابة عن سؤال الاراسة الفرعي الأول ما مدى الاحتياج للمفردات المتضمنة في مقرر بناء وتطوير المناهج الحالي من وجهة نظر أساتذة المقر والطلاب والطالبات

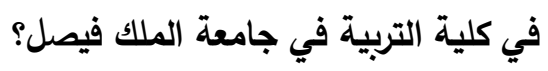

للإجابة عن هذا السؤال، تم احتساب المتوسطات الحسابية والانحرافات المعيارية ومدى الاحتياج لكل فقرة من فقرات

المحاور الثلاثة، كما يُظهرها الجدول (ع) ).

يتبين من خلال الجدول (ع) التفاوت في وجهات نظر الطلاب والطالبات حول مدى الاحتياج لمضمون كل فقرة من فقرات

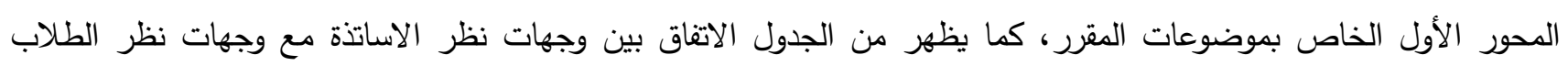

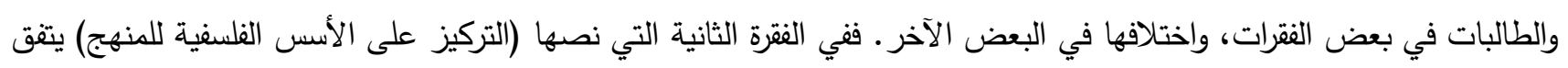

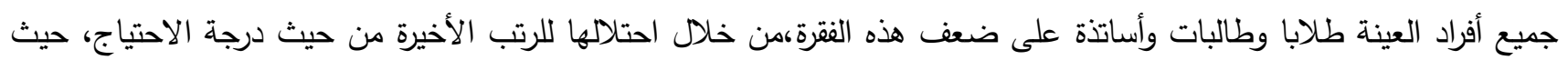

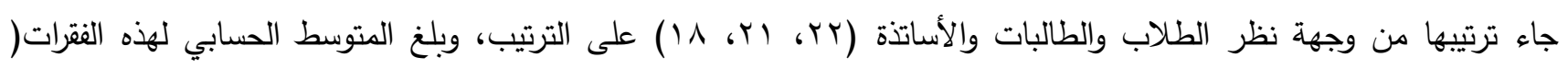

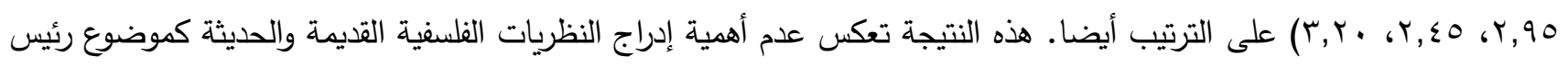
في مقرر بناء وتطوير المناهج، فالتوجهات الحديثة لا تستند في مرجعيتها إلى عالم المثل وتقسيمات المواضيع التي نادى بهات التها

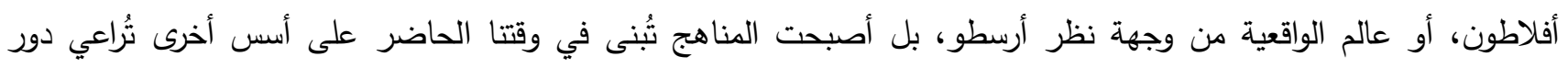
الطالب كمشارك فاعل في العملية التعليمية. 
الجدول (؛ ): المتوسطات الحسابية والانحرافات المعيارية ومدى الاحتياج للمفردات المتضمنة في مقرر بناء المناهج

\begin{tabular}{|c|c|c|c|c|c|c|c|c|c|c|c|c|c|c|c|}
\hline \multicolumn{4}{|c|}{ أساتذة المقرر } & \multirow{2}{*}{ 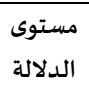 } & \multirow{2}{*}{ 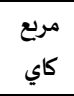 } & \multicolumn{4}{|c|}{ 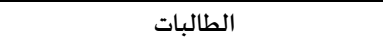 } & \multicolumn{4}{|c|}{ الطلاب } & \multirow[t]{2}{*}{ الفقرات } & \multirow[t]{2}{*}{ r } \\
\hline الترتيب & $*_{2}$ & ${ }^{*} \tau$ & $*_{\mathrm{i}}$ & & & الترتيب & $*_{2}$ & ${ }^{*} \tau$ & $*^{5}$ & الترتيب & $*_{2}$ & ${ }^{*} \tau$ & s & & \\
\hline$\varepsilon$ & كبير & 1.70 & 4.00 & دالة & $11,1 \mathrm{r}$ & o & كبير & 1.21 & 3.64 & 1 & كبير & 0.99 & 3.93 & التمييز بين مفهومي المنهجج: التقليدي والحديث & 1 \\
\hline 11 & متوسط & 1.48 & 3.20 & دالة & $\mid r, \varepsilon \varepsilon$ & ri & ضعيف & 1.21 & 2.45 & 22 & متوسط & 0.98 & 2.95 & التركيزعلى الأسس الفلسفية للمنهج & r \\
\hline$r$ & كبير & 1.07 & 4.40 & دالة & 10,15 & ir & متوسط & 1.72 & 3.18 & $T$ & كبير & 1.12 & 3.59 & تضمين الأساس العقدي (الدين الإسلامي) للمنهج & $r$ \\
\hline - & كبير & 1.70 & 4.00 & دالة & $1 r, 01$ & 1 & كبيرجدا & 1.42 & 4.27 & 8 & كبير & 1.12 & 3.57 & التعرف على الأسس النفسية للمنهج & $\varepsilon$ \\
\hline 1 & كبير & 0.70 & 4.60 & دالة & $r, \Lambda \Lambda$ & $r$ & كبير & 1.56 & 3.73 & 3 & كبير & 0.90 & 3.69 & ربط المنيج بالمجتمع ومشكلاته & 。 \\
\hline 1 & كبير & 1.20 & 3.90 & دالة & $q, \Psi \varepsilon$ & $\varepsilon$ & كبير & 1.56 & 3.73 & 13 & كبير & 1.27 & 3.41 & ربط المنهج بالتطور التكنولوجي & 7 \\
\hline 19 & متوسط & 1.37 & 2.90 & دالة & $7, Y Y$ & rr & ضيعيف & 1.41 & 2.00 & 18 & متوسط & 1.25 & 3.31 & شرح الأهداف السلوكية ومجالاتها ومستوباتها & $\mathrm{v}$ \\
\hline $1 \varepsilon$ & كبير & 1.27 & 3.50 & دالة & 7,49 & 17 & متوسط & 1.04 & 2.91 & 4 & كبير & 1.02 & 3.65 & ومبادئ) & ^ \\
\hline r. & متوسط & 1.25 & 2.70 & دالة & $7, \mathrm{Vr}$ & IE & متوسط & 1.64 & 3.09 & 10 & كبير & 1.15 & 3.57 & تحديد طرق واستراتيجيات تدربس الطلبة & 9 \\
\hline ir & كبير & 1.43 & 3.50 & دالة & 1,07 & ^ & كبير & 1.29 & 3.55 & 6 & كبير & 1.16 & 3.60 & التعرف إلى إجراءات تصميم الأنشطة في المنزيج & 1. \\
\hline rr & ضعيف & 1.43 & $\mathbf{2 . 5 0}$ & دالة & $v, 74$ & r. & متوسط & 1.56 & 2.73 & 20 & متوسط & 1.18 & 3.27 & تعريف الوسائل التعليمية وأنواعها واستخداماتها & 11 \\
\hline ri & متوسط & 0.95 & $\mathbf{2 . 7 0}$ & دالة & $11, \mathrm{TV}$ & iv & متوسط & 1.58 & 2.91 & 14 & متوسط & 1.10 & 3.39 & التعرف على إجراءات تقويم تعلم الطلبة & ir \\
\hline 1. & كبير & 1.64 & 3.70 & دالة & $1 \mathrm{~T}, \mathrm{TV}$ & 11 & متوسط & 1.42 & 3.27 & 9 & كبير & 1.18 & 3.57 & تعريف منهج المواد المنفصلة وتطبيقاته & ir \\
\hline 10 & كبير & 1.65 & 3.50 & دالة & $1 \wedge, \varepsilon \varepsilon$ & $r$ & كبير & 1.30 & 3.91 & 16 & متوسط & 1.18 & 3.35 & تعريف منيج النشاط ومميزاته & $1 \varepsilon$ \\
\hline 17 & كبير & 1.58 & 3.50 & دالة & $10, \pi r$ & $\pi$ & متوسط & 1.66 & 3.18 & 15 & متوسط & 1.15 & 3.36 & تعريف المننجج المحتوري ومميزاته & 10 \\
\hline$\Lambda$ & كبير & 1.32 & 3.80 & دالة & 7,77 & 9 & كبير & 1.44 & 3.55 & 2 & كبير & 1.05 & 3.75 & تعريف منهج الوحدات ومميزاته & 17 \\
\hline iv & متوسط & 1.42 & 3.30 & دالة & $v, r \varepsilon$ & 19 & متوسط & 1.66 & 2.82 & 21 & متوسط & 1.17 & 3.16 & التعنوفوفي) تنظيمات حديثة للمنيج (البيئي & iv \\
\hline 11 & كبير & 1.64 & 3.70 & دالة & $7,7 V$ & 7 & كبير & 1.12 & 3.64 & 11 & كبير & 1.09 & 3.57 & تعريف عملية تقويم المنتج وإجراءاتها & 11 \\
\hline 9 & كبير & 1.69 & 3.80 & دالة & 7,19 & $\mathrm{r}$ & كبير & 1.43 & 3.64 & 5 & كبير & 1.13 & 3.65 & تعريف عملية تطوير المنتج وإجراءاتها & 19 \\
\hline$r$ & كبيرجدا & 0.84 & 4.40 & دالة & $9, r)$ & 10 & متوسط & 1.81 & 3.09 & 12 & كبير & 1.30 & 3.57 & تطوبرالمنجج على تجربة المملكة العربية السعودية في & r. \\
\hline ir & كبير & 1.17 & 3.60 & دالة & 1,07 & 14 & متوسط & 1.30 & 2.91 & 17 & متوسط & 1.24 & 3.32 & الاطلاع على تجارب الدول العربية في تطوير المنمجج & ri \\
\hline $\mathrm{v}$ & كبير & 0.99 & 3.90 & دالة & $r, 79$ & 1. & كبير & 1.63 & 3.55 & 19 & متوسط & 1.29 & 3.28 & الاطلاع على تجارب الدول الأجنبية في تطوير المنميج & rr \\
\hline
\end{tabular}

* (م) رمز المتوسط الحسابي و(ح) رمز الانحراف المعياري و(د) رمز مدى الاحتياج في الجداول \& ؛، ه، 1.

وتتنوع فيها مصادر التعلم ما بين المصادر المطبوعة وتلك الالكترونية، كما توظف التكنولوجيا بشكل رئيس من خلال مواقع التواصل الاجتماعي والعالم الافتراضي. كما اتفق أفراد الدراسة على الفقرة السابعة من المحور ذاته ونصها (شرح الأهداف السلوكية ومجالاتها ومستوياتها)، حيث

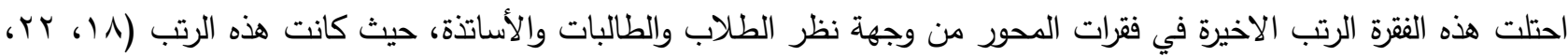

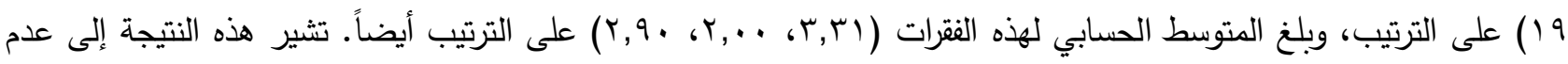
التوسع في تقديم مجالات ومستويات الاهداف السلوكية بالرغم من أهميتها؛ فالمهم هنا تعريف الطالب المبتدئ بالهدف السلوكي

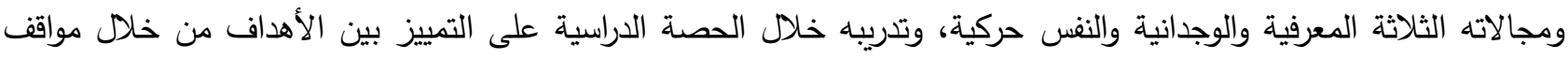

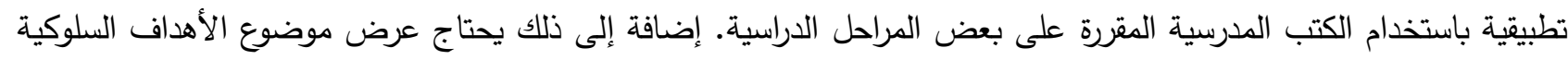

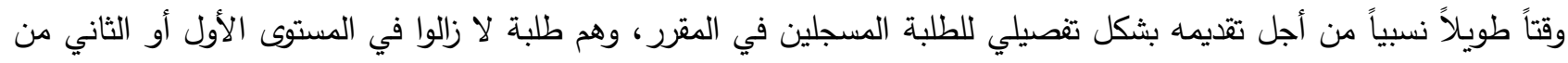
مرحلتهم الجامعية الأولى، وقد اجتازوا حديثا الثانوية العامة، وربما يكون هذا من القرارات التي تجدر مراجعتها من قبل فريق إعداد الخطط في كلية التربية في جامعة الملك فيصل لتأخير مقرر بناء وتطوير المناهج، والبدء في تقديمه اعتبارا من المستوى الخامس، ويكون له متطلبات سابقة تساعد في استيعاب معظم مغرداته إن لم يكن كلها. 
كذلك اتفق أفراد الدراسة على الفقرة الحادية عشر من المحور ذاته ونصها (تعريف الوسائل التعليمية وأنواعها واستخداماتها)،

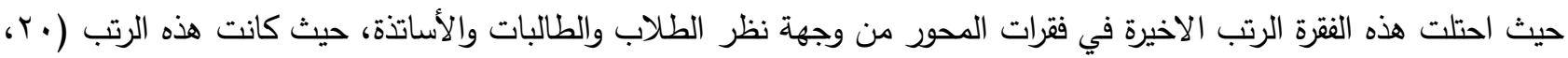

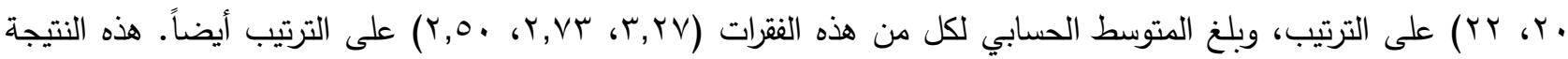

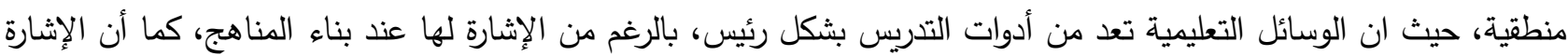
إلى ضعف الاحتياج لها مبرر بوجود مقرر خاص بعنوان (تصميم وإنتاج الوسائل التعليمية) يقدمه قسم تقنيات التعليم في كلية

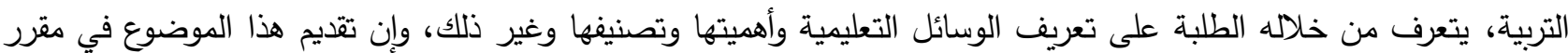
بناء وتطوير المناهج يُخل بمصفوفة المدى والتتابع للمقررات الدراسية التي تقدمها الكلية في التخصصات المختلفة. فقرة أخرى تم الاتفاق عليها هي الفقرة السابعة عشر ونصها (التعرف على تتظيمات حديثة للمنهج (البيئي والتكنولوجي

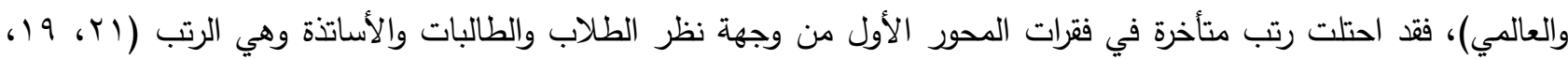

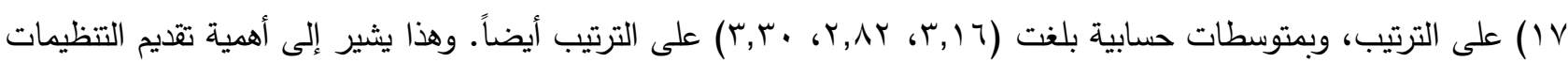

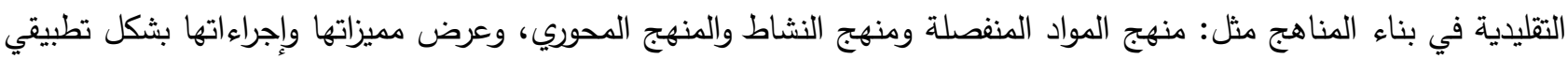
- ما أمكن - على الطلبة من خلال الكتب المدرسية، وبهذا يتم تمهيد الطريق للطالب بالاطلاع ولو بشكل ذاتي على تتظيمات وعني

في الفقرة الأولى من فقرات المحور الأول ونصها (التمييز بين مفهومي المنهج: التقليدي والحديث)، تم الإجماع على أهميتها

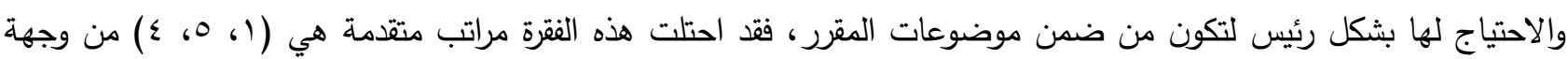

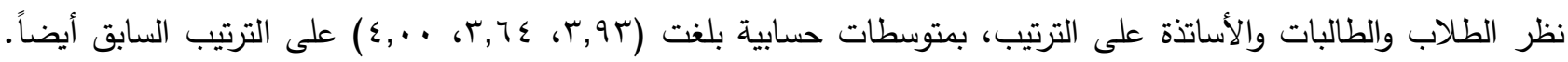
وهذا يشير إلى أهمية أن يدرك الطلبة الفرق بين المنهج بمفهومه التقليدي والمنهج بمفهومه غير التقليدي (أو الحديث أو الواسع)

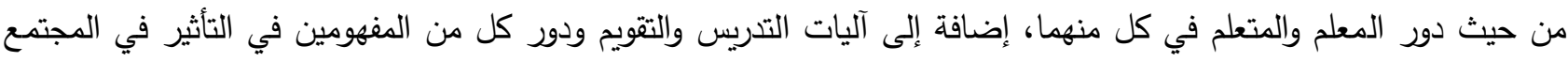

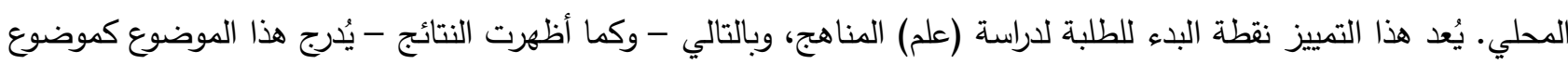
رئيس ويُعْدم في طليعة موضوعات هذا المقرر . لمدات

وأظهرت النتائج الواردة في الجدول (ع) أهمية الفقرة الخامسة ونصها (ربط المنهج بالمجتمع ومشكلاته)، حيث احتلت أيضا

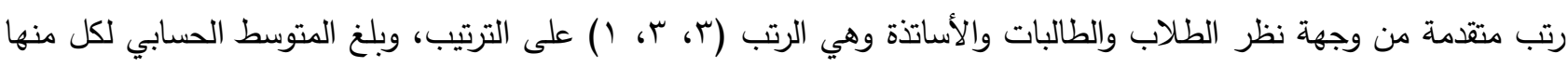

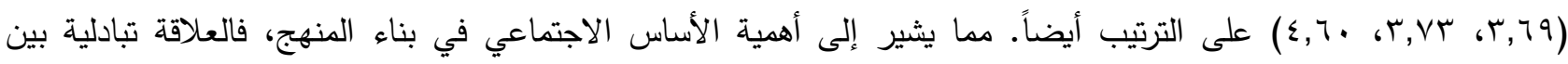
المناهج والمجالات الأخرى، فالمنهج يؤثر في ثتافة المجتمع ويتأثر بها، كذلك بالنسبة لمجالات الاقتصاد والسياسة والتكنولوجيا

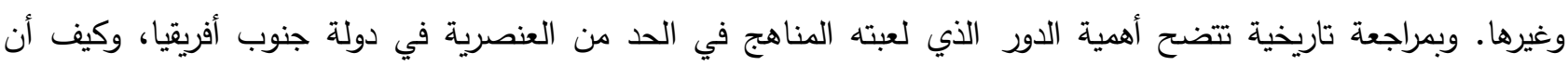

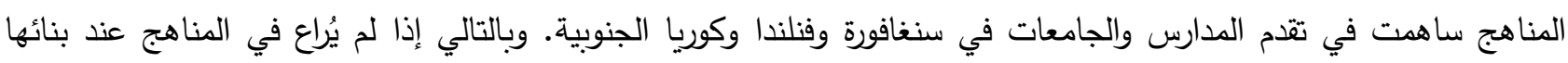
المجتمع بكافة أفراده ومؤسساته وثقافته وعاداته وتقاليده ومشكلاته والتحديات التي يواجهها، فستبقى حشواً للمفاهيم والحقائق النظرية التي لا تؤهل الفرد للتكيف مع متطلبات الحياة ومستجداتها المتسارعة. يُشار ومن خلال النتائج في الجدول (ع) أهمية الفقرة ·r من فقرات المحور الأول ونصها (الاطلاع على تجربة المملكة

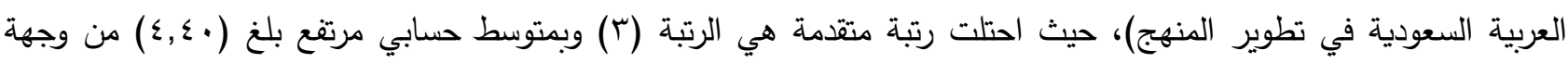

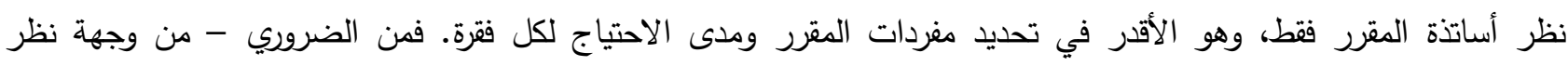

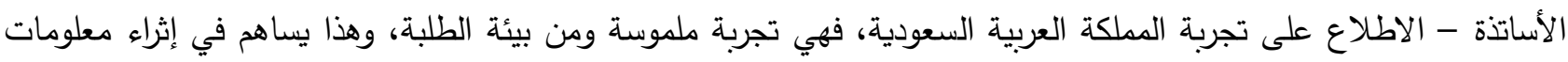

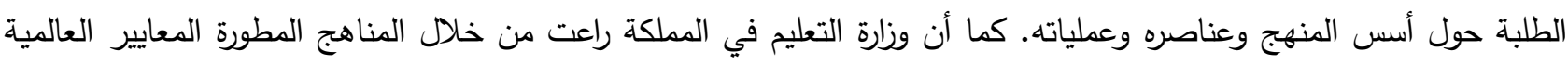

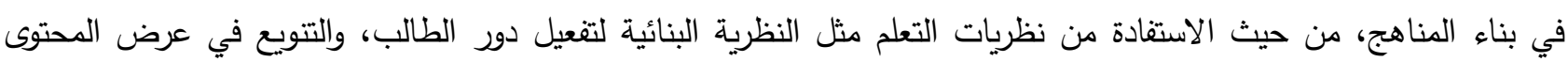
وعدم اقتصاره على الطريقة اللفظية، وكذلك إرشاد الطلبة إلى مصادر التعلم الإكترونية ذات الصلة بموضوع الدرس، بالإضافية دونة 
إلى تضمين المحتوى عدد كبير من الأنشطة تتم مناقشتها سواء داخل الغرفة الصفية أم خارجها. هذه تجربة غنية يجدر تضمينها كموضوع رئيس في مقرر بناء وتطوير المناهج، ومناقشة تفصيلاتها وإجراءاتها بشكل تطبيقي أمام الطلبة، بما يساعدهم مستقبلاً

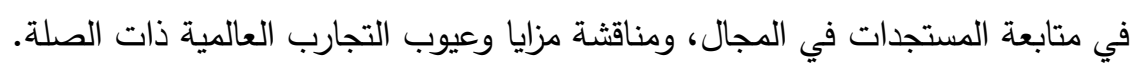

$$
\text { الإجابة عن سؤال الدراسة الفرعي الثاني }
$$

ما مدى الاحتياج للإجراءات التدريسية المطبقة في مقرر بناء وتطوير المناهج الحالي من وجهة نظر أساتذة المقرر والطلاب

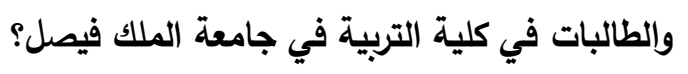
للإجابة عن هذا السؤال، تم احتساب المتوسطات الحسابية والانحرافات المعيارية ومدى الاحتياج لكل فقرة من فقرات المحاور

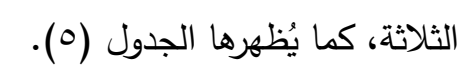
أظهرت النتائج في الجدول (0) وجهات نظر كل من الطلاب والطالبات والأساتذة في فقرات محور الاستبانة الثاني الخاص بإجراءات تقديم المقرر، حيث ظهر التوافق في بعض الفقرات والاختلاف في الفقرات الأخرى. فالفقرة بr ونصها (درجة الواجبات

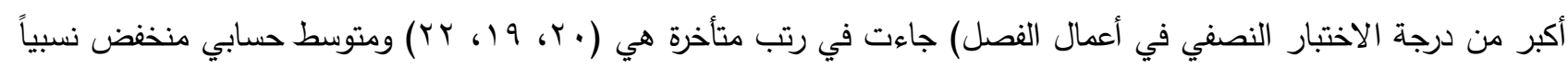

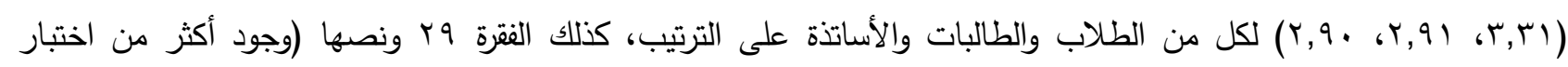

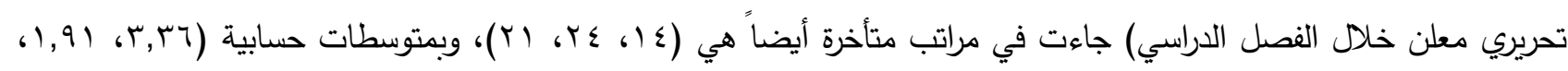

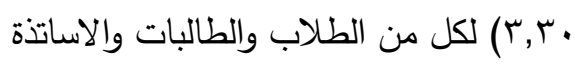


الجدول (ه): المتوسطات الحسابية والانحرافات المعيارية ومدى الاحتياج لإجراءات تنفيذ مقرر بناء المناهج

\begin{tabular}{|c|c|c|c|c|c|c|c|c|c|c|c|c|c|c|c|}
\hline \multicolumn{4}{|c|}{ أسـاتذة المقرر } & \multirow{2}{*}{ مستو } & \multirow{2}{*}{ 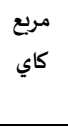 } & \multicolumn{4}{|c|}{ 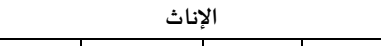 } & \multicolumn{4}{|c|}{ الذكور } & \multirow[t]{2}{*}{ 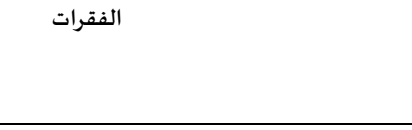 } & \multirow[t]{2}{*}{ م } \\
\hline الترتي & د & $\tau$ & م & & & 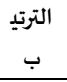 & د & $\tau$ & م & 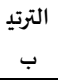 & د & $\tau$ & م & & \\
\hline 11 & كبير & $\begin{array}{c}1.3 \\
7\end{array}$ & 4.10 & دالة & $7, \wedge 1$ & 9 & كبير & 1.44 & 3.45 & 6 & كبير & 1.24 & 3.63 & تحديد أهداف المقرر & rr \\
\hline 5 & 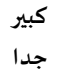 & $\begin{array}{c}0.6 \\
7\end{array}$ & 4.30 & دالة & $\Lambda, T V$ & 17 & متوسط & 1.38 & 3.09 & 3 & كبير & 1.20 & 3.85 & تدريس المقرر داخل غرفة الصف & $r \varepsilon$ \\
\hline 17 & 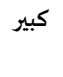 & $\begin{array}{c}1.2 \\
6\end{array}$ & 3.60 & دالة & $\Lambda, r q$ & 14 & متوسط & 1.40 & 3.18 & 13 & متوسط & 1.28 & 3.36 & تقديم أنشطة لا صفية لإثراء الموضوعات & ro \\
\hline 6 & 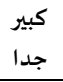 & $\begin{array}{c}1.4 \\
9 \\
\end{array}$ & 4.30 & دالة & 1,99 & 11 & متوسط & 1.91 & 3.36 & 2 & كبير & 1.21 & 3.87 & تقديم خطة المقرر في المحاضرة الأولى & r \\
\hline 15 & 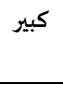 & $\begin{array}{c}1.6 \\
2\end{array}$ & 3.80 & دالة & $7, r r$ & 5 & 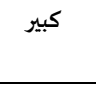 & 1.58 & 3.91 & 1 & 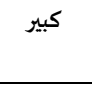 & 1.14 & 4.05 & وتوزيع درجات المقرر على اختبارنصيفي ونهائي & TV \\
\hline 22 & سطو & $\begin{array}{c}1.5 \\
2\end{array}$ & 2.90 & دالة & 7,19 & 19 & متوسط & 1.64 & 2.91 & 20 & متوسط & 1.48 & 3.31 & 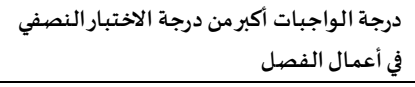 & ru \\
\hline 21 & سطو & $\begin{array}{c}1.5 \\
7\end{array}$ & 3.30 & دالة & $9, \varepsilon 0$ & 24 & ضعيف & 1.58 & 1.91 & 14 & متوسط & 1.47 & 3.36 & والفصل الدراسي من اختبار تحريري معلن خلال & rq \\
\hline 25 & ضبعي & $\begin{array}{c}1.6 \\
5\end{array}$ & 2.50 & دالة & $\gamma, r \varepsilon$ & 7 & كبير & 1.68 & 3.73 & 22 & متوسط & 1.42 & 3.13 & اشتمال الاختبارات على أسئلة موضوعية فقط & $r$. \\
\hline 26 & ضبعي & $\begin{array}{c}1.4 \\
2 \\
\end{array}$ & 2.30 & دالة & $11, \varepsilon$ & 25 & ضعيف & 1.33 & 1.82 & 26 & متوسط & 1.49 & 2.80 & اشتمال الاختبارات على أسئلة مقالية فقط & r \\
\hline 7 & 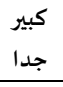 & $\begin{array}{c}1.0 \\
6\end{array}$ & 4.30 & دالة & 8,11 & 18 & متوسط & 1.51 & 3.09 & 12 & 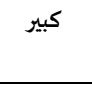 & 1.52 & 3.41 & اتباع طريقة المحاضرة في التدريس & rr \\
\hline 23 & سطو & $\begin{array}{c}1.5 \\
7\end{array}$ & 2.70 & دالة & $1 r, \Lambda$ & 22 & ضعيف & 1.21 & 2.55 & 17 & متوسط & 1.37 & 3.35 & الأسئلة في الاختبارات موضوعية ومقالية & Tr \\
\hline 9 & كبير & $\begin{array}{c}1.3 \\
2\end{array}$ & 4.20 & دالة & $\Lambda, 77$ & 1 & كبيرجدا & 1.29 & 4.45 & 10 & كبير & 1.36 & 3.44 & تنويع طرق التدريس لتقديم مفردات المقرر & $r \varepsilon$ \\
\hline 20 & 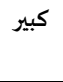 & $\begin{array}{c}1.6 \\
5\end{array}$ & 3.40 & 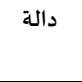 & $\Lambda, \varepsilon 0$ & 20 & متوسط & 1.66 & 2.82 & 7 & 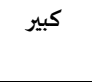 & 1.31 & 3.53 & استخدام السبورة والأقلام الملونة & ro \\
\hline 3 & كبير & $\begin{array}{c}0.7 \\
1 \\
\end{array}$ & 4.50 & 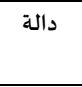 & $\mathrm{V}, \wedge \mathrm{9}$ & 4 & كبير & 1.55 & 4.00 & 19 & متوسط & 1.36 & 3.32 & استخدام أجهزة العرض (DATA SHOW) & m \\
\hline 24 & سطو & $\begin{array}{c}1.3 \\
4 \\
\end{array}$ & 2.70 & 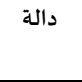 & $V, I Y$ & 15 & متوسط & 1.83 & 3.18 & 4 & 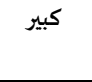 & 1.10 & 3.75 & يكفي سـاعتان أسبوعيا لتغطية مفردات المقرر & rv \\
\hline 12 & 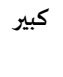 & $\begin{array}{c}1.2 \\
0\end{array}$ & 4.10 & 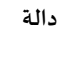 & $9, r r$ & 23 & ضعيف & 1.47 & 2.18 & 15 & متوسط & 1.40 & 3.36 & تقديم الطلبة عروض ذات صلة أمام زملايهم & ro \\
\hline 18 & 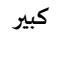 & $\begin{array}{c}1.5 \\
8\end{array}$ & 3.50 & 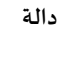 & 9,11 & 8 & 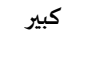 & 1.79 & 3.73 & 11 & 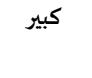 & 1.28 & 3.44 & إعادة أوراق الإجابة للاختبار للطلبة & rq \\
\hline 16 & كبير & $\begin{array}{c}1.7 \\
7\end{array}$ & 3.70 & 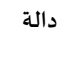 & $9, \wedge 1$ & 2 & كبيرجدا & 1.43 & 4.36 & 9 & كبير & 1.38 & 3.51 & مناقشة إجابات الطلبة بعد تصحيح الاختبار & $\varepsilon$. \\
\hline 1 & كبير & $\begin{array}{c}0.0 \\
0 \\
\end{array}$ & 5.00 & دالة & $10, \varepsilon$ & 6 & كبير & 1.83 & 3.82 & 16 & متوسط & 1.49 & 3.36 & وجود قاعات صفية مهيأة للعمل التعاوني & $\varepsilon$ \\
\hline 10 & 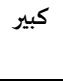 & $\begin{array}{c}1.4 \\
0 \\
\end{array}$ & 4.20 & دالة & $1 \varepsilon, r$ & 12 & متوسط & 1.63 & 3.36 & 18 & متوسط & 1.30 & 3.33 & القاعات الصفية ذات تهوية وإضـاءة مناسبة & $\varepsilon r$ \\
\hline 4 & كبير & $\begin{array}{c}0.8 \\
5 \\
\end{array}$ & 4.50 & 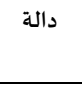 & $1 \varepsilon, V$ & 21 & متوسط & 1.57 & 2.64 & 23 & متوسط & 1.33 & 3.12 & أعداد الطلبة في القاعة التدريسية أقل من ·r & $\varepsilon r$ \\
\hline 2 & كبير & $\begin{array}{c}0.7 \\
0 \\
\end{array}$ & 4.60 & دالة & $\Lambda, 00$ & 3 & 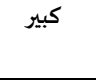 & 1.38 & 4.09 & 8 & كبير & 1.27 & 3.53 & تفعيل المناقشات الصيفية وإثارة الأسئلة & $\varepsilon \varepsilon$ \\
\hline 19 & 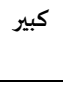 & $\begin{array}{c}1.6 \\
5 \\
\end{array}$ & 3.50 & 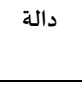 & $v, 01$ & 26 & ضعيف & 1.35 & 1.73 & 24 & متوسط & 1.42 & 3.08 & وجود أكثرمن مدرس لتقديم محتوى المقرر & $\varepsilon_{0}$ \\
\hline 14 & 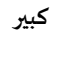 & $\begin{array}{c}1.4 \\
1\end{array}$ & 4.00 & 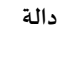 & $\Lambda, \varepsilon r$ & 10 & 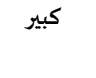 & 1.69 & 3.45 & 25 & متوسط & 1.40 & 3.05 & تصحيح التكليفات وإعادتها للطلبة & $\varepsilon 7$ \\
\hline 13 & 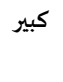 & $\begin{array}{c}1.5 \\
2\end{array}$ & 4.10 & 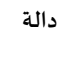 & $\Lambda, 91$ & 16 & متوسط & 1.72 & 3.18 & 5 & 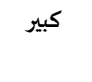 & 1.15 & 3.72 & مناسبة الاختبارات لمحتوى المقرر & $\varepsilon v$ \\
\hline 8 & كبير & $\begin{array}{c}0.8 \\
2 \\
\end{array}$ & 4.30 & 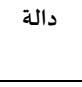 & $V, I r$ & 13 & متوسط & 1.62 & 3.27 & 21 & متوسط & 1.37 & 3.21 & تقديم المقرر بشكل تطبيقي & $\varepsilon \wedge$ \\
\hline
\end{tabular}




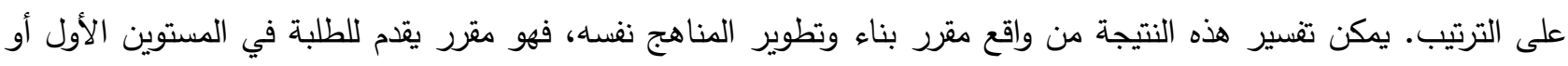

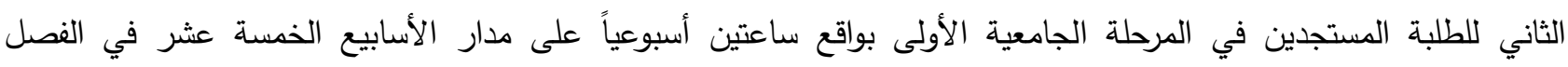

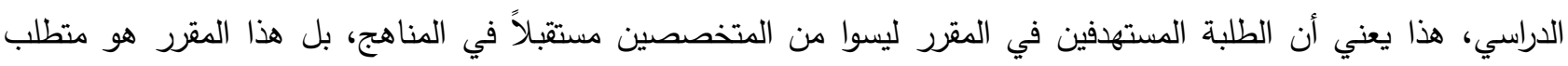

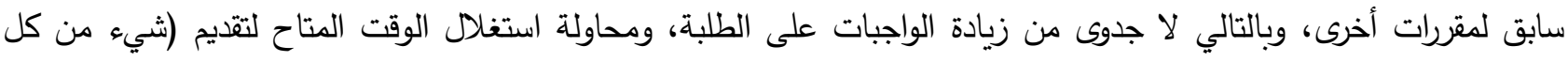

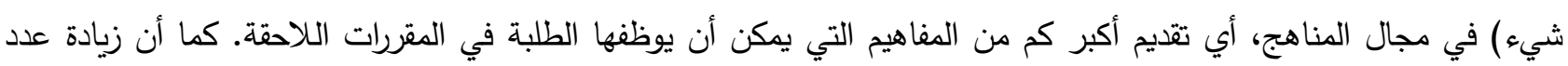

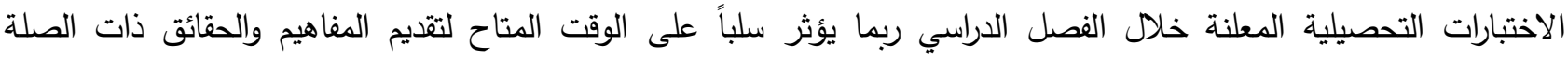
بالمقرر، ويحول دون تغطيتها بشكل كامل.

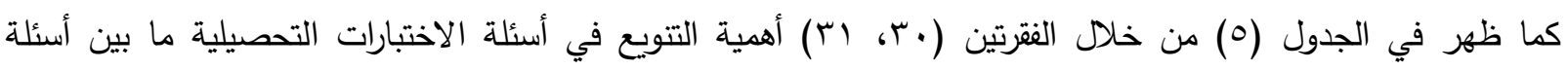

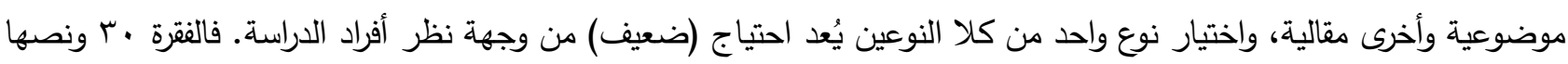

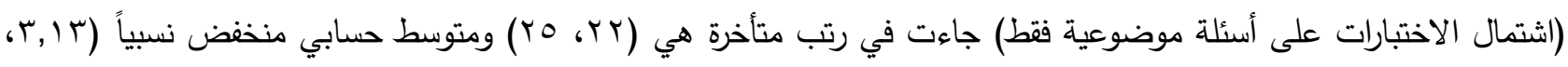

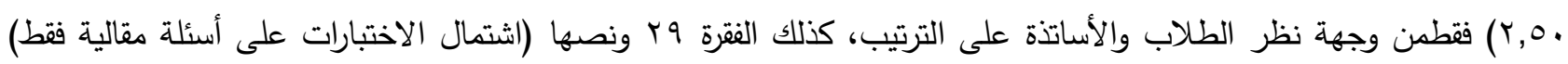

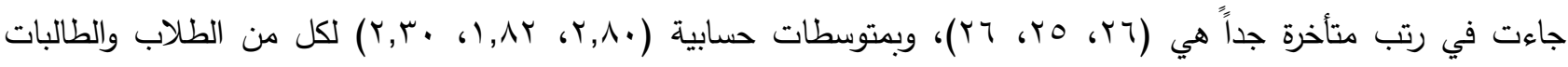

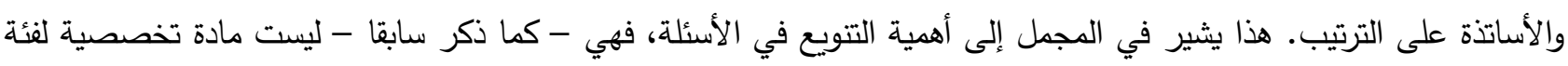

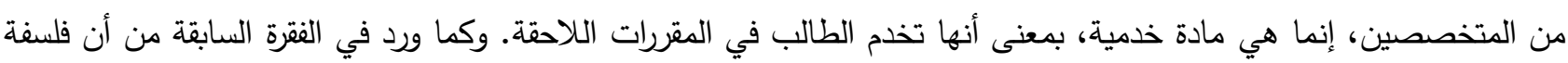

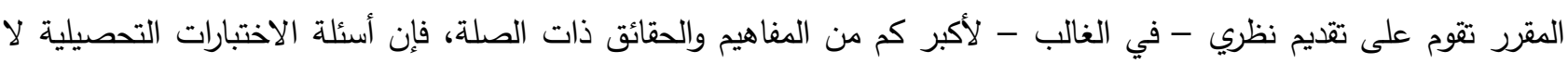

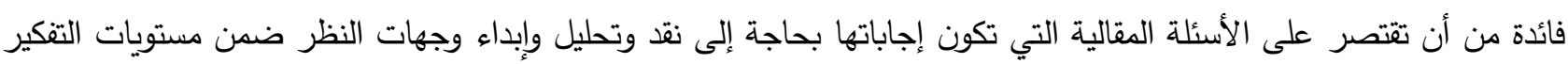

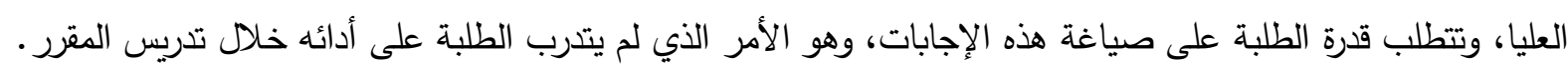

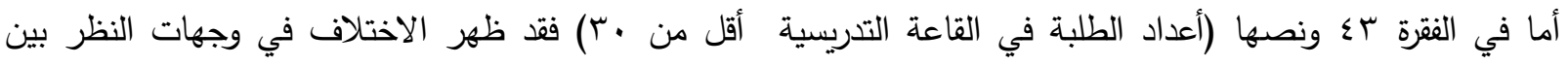

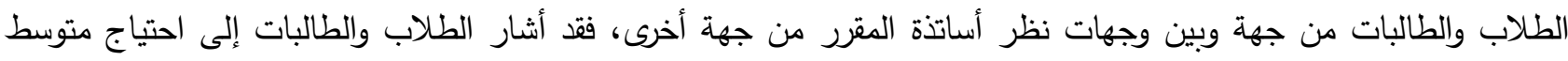

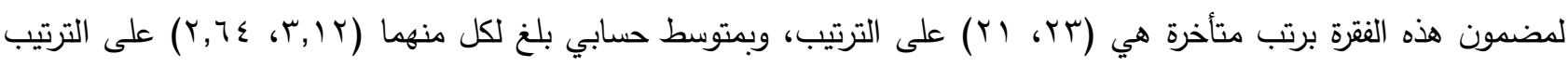

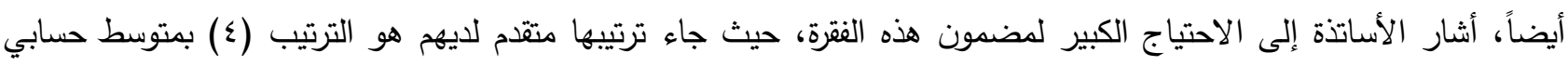

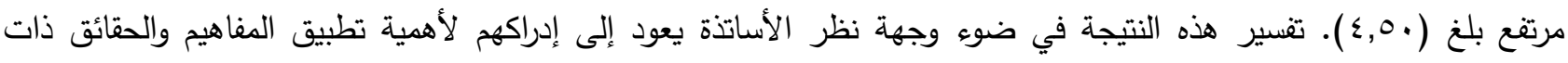

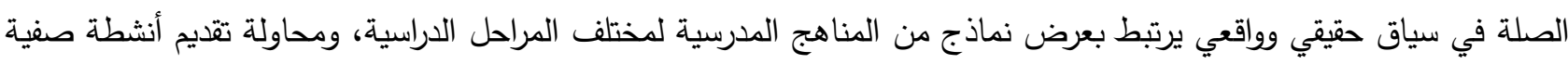

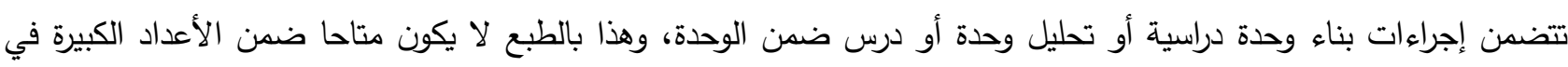

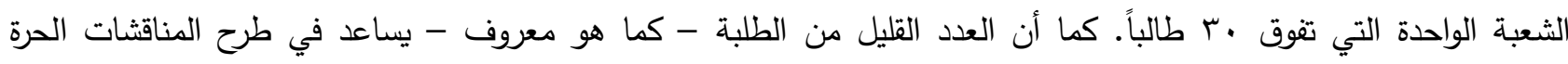

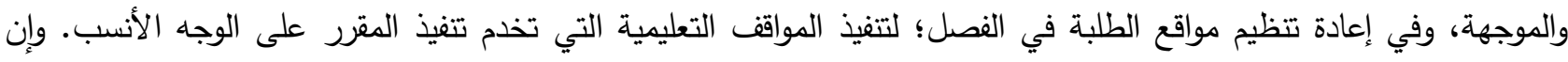

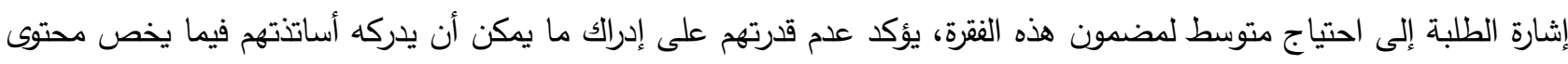
المقرر وإجراءات تتفيذه.

وفي الفقرة 0 ونصها (وجود أكثر من مدرس لتقديم محتوى المقرر)، لم تظهر النتائج احتياجا كبيرا لتقديم المقرر من خلال

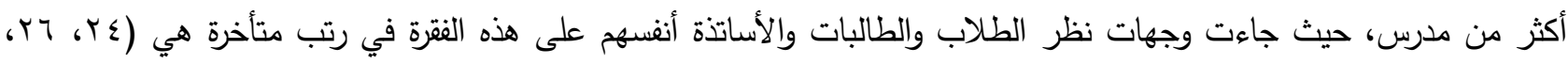

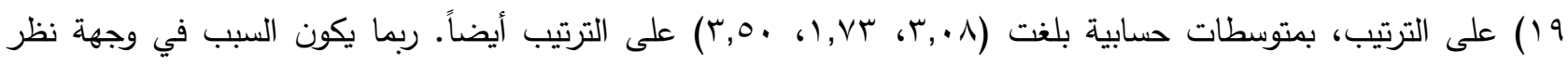

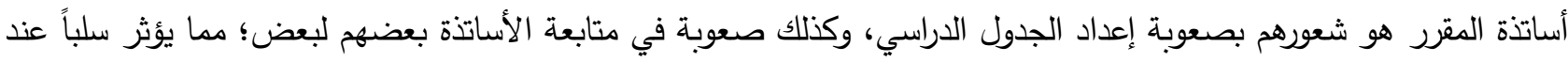

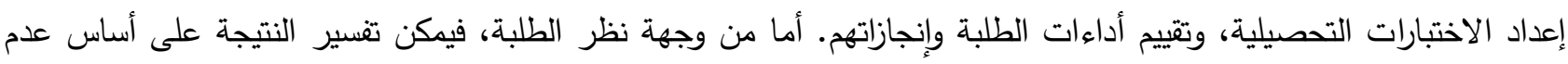

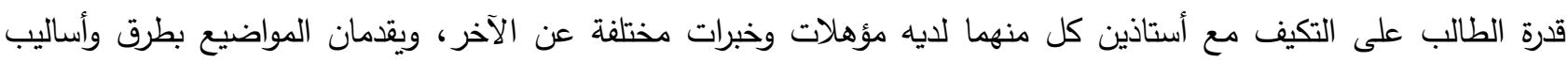
مختلفة، وهذا كله ينعكس على أداء الطالب وتحصيله النهائي. 
الإجابة عن سؤال الدراسة الفرعي الثالث ما مدى الاحتياج لمصادر التعلم المستخدمة في مقرر بناء وتطوير المناهج الحالي من وجهة نظر أساتذة المقرر والطلاب

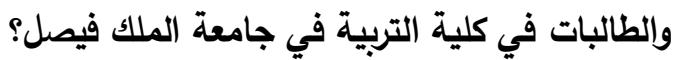
للإجابة عن هذا السؤال، تم احتساب المتوسطات الحسابية والانحرافات المعيارية ومدى الاحتياج لكل فقرة من فقرات المحاور الثلاثة، كما يُظهرها الجدول (T). تُظهر النتائج في الجدول (†) وجهات نظر كل من الطلاب والطالبات والأساتذة في فقرات محور الاستبانة الثالث الخاص

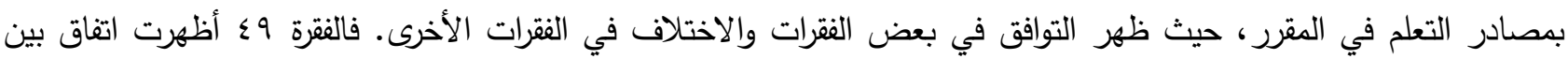

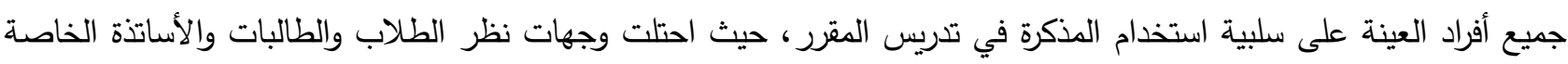

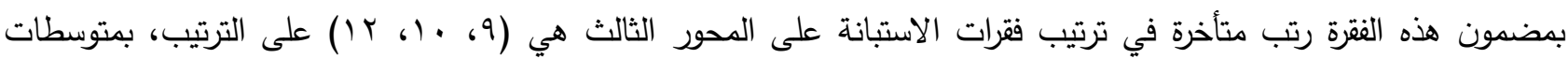

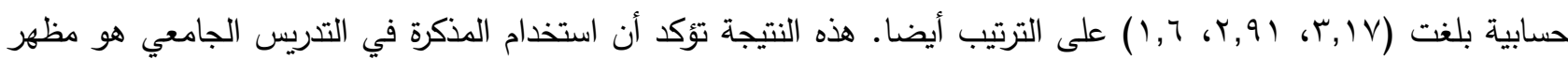
من مظاهر الاستسهال للى بعض الأساتذة وبعض الطلبة في تقديم المقرر، فهي تقدم المفاهيم والحقائق ذات الصلة بشكل جزئي وليس متكامل يتيح الفرصة للطالب أن يطور نفسه في هذا المجال مستقبلاً. كما أن استخدام المذكرة هو إشعار للطلبة بأن

الجدول (†): المتوسطات الحسابية والانحرافات المعيارية ومدى الاحتياج لمصادر التعلم في مقرر بناء المناهج

\begin{tabular}{|c|c|c|c|c|c|c|c|c|c|c|c|c|c|c|c|}
\hline \multicolumn{4}{|c|}{ أساتذة المقرر } & \multirow{2}{*}{ مستوى } & \multirow{2}{*}{ كريع } & \multicolumn{4}{|c|}{ الإناث } & \multicolumn{4}{|c|}{ الذكور } & \multirow[t]{2}{*}{ الفقرات } & \multirow[t]{2}{*}{ م } \\
\hline الترتيب & د & $\tau$ & م & & & الترتيب & د & $\tau$ & م & الترتيب & د & $\tau$ & م & & \\
\hline 12 & ضديف & 0.84 & 1.60 & دالة & 7,11 & 10 & متوسط & 1.58 & 2.91 & 9 & متوسط & 1.60 & 3.17 & تلخيص لمحتوى مذكرة فيها & $\varepsilon q$ \\
\hline 4 & كبير & 1.45 & 3.90 & دالة & $11, r$ & 2 & كبير & 1.64 & 3.91 & 1 & كبير & 1.35 & 3.83 & تشتحديد كتاب واحد على محتوى & 0. \\
\hline 11 & متوسط & 1.73 & 2.90 & دالة & $\mid r, \varepsilon$ & 12 & ضعيف & 1.85 & 2.27 & 12 & متوسط & 1.46 & 3.04 & مراجع متعدددة & 01 \\
\hline 9 & متوسط & 1.49 & 3.00 & دالة & 1,99 & 7 & متوسط & 1.68 & 3.27 & 11 & متوسط & 1.28 & 3.12 & 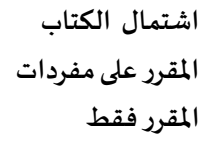 & or \\
\hline 10 & متوسط & 1.70 & 3.00 & دالة & $7, r r$ & 11 & متوسط & 1.66 & 2.82 & 10 & متوسط & 1.26 & 3.17 & المقرجعي ومفرداب المقرر كتاب & or \\
\hline 6 & كبير & 1.77 & 3.70 & دالة & 7,91 & 4 & متوسط & 1.63 & 3.36 & 2 & كبير & 1.27 & 3.64 & حديث في طباعته المقرر & $0 \varepsilon$ \\
\hline 7 & كبير & 1.57 & 3.70 & دالة & 10,11 & 8 & متوسط & 1.54 & 3.18 & 5 & كبير & 1.12 & 3.53 & ترتيب محتباب متوافق مع & 00 \\
\hline 8 & كبير & 1.35 & 3.40 & دالة & 9,11 & 9 & متوسط & 1.51 & 2.91 & 7 & متوسط & 1.27 & 3.39 & الموضيو المتاب المقرر يقدم & 07 \\
\hline
\end{tabular}




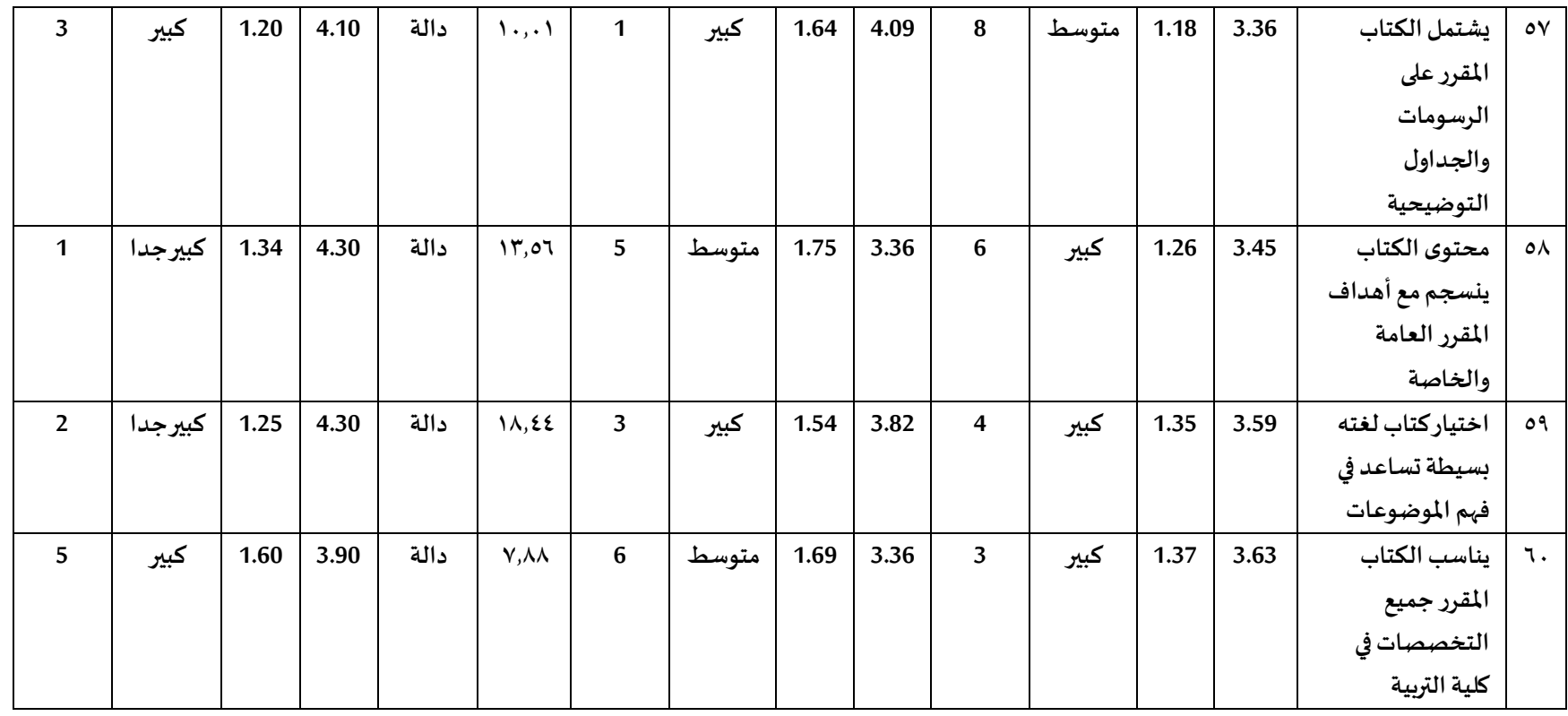

* (م) رمز المتوسط الحسابي و(ح) رمز الانحراف المعياري و(د) رمز مدى الاحتياج في الجداول ؛، ه، 7.

للمقرر ما هو إلى مفاهيم جامدة مجردة لا يتطلب حفظها لتجاوز الاختبارات التحصيلية، والحصول على تقدير عال في المقرر ،.

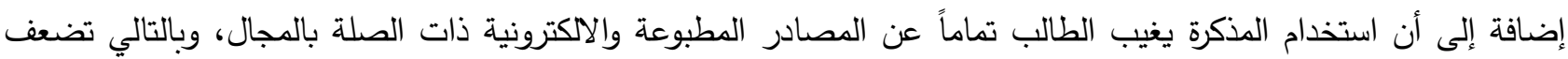
لديه مهارة البحث العلمي التي تسعى الجامعة في الأساس إلى تتميتها لدى المتعلمين.

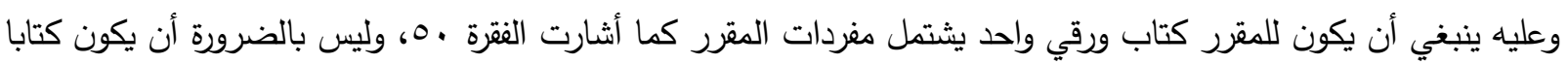

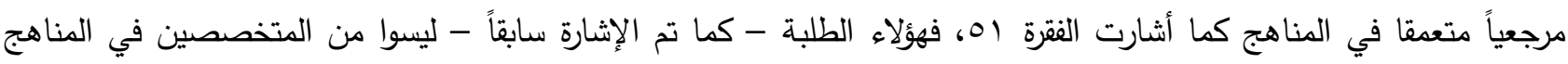

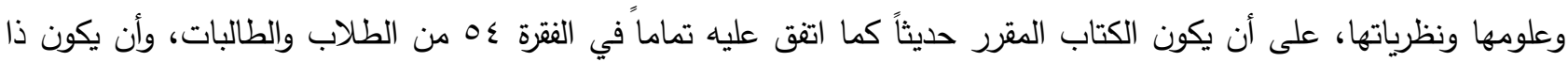
لغة بسيطة وسهلة كما اتفق عليه من قبل الطلاب والطالبات والأساتذة أنفههم. الإجابة عن سؤال الدراسة الفرعي الرابع هل يوجد فرق ذو دلالة إحصائية (عند مستوى لمفردات المقرر الحالي وإجراءات تنفيذه ومصادر التعلم الخاصة بهـ دله للإجابة عن هذا السؤال تم احتساب قيمة مربع كاي باستخدام برمجية SPSS لجميع فقرات الاستبانة، فكانت النتيجة أن قيم

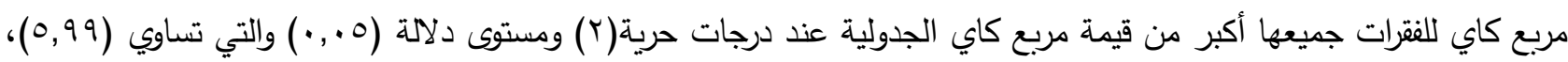
وهذا يشير إلى رفض الفرضية الصفرية " لا يوجد فروق ذات دلالة إحصائية (عند مستوى الذكور والإناث فيما يتعلق بمدى الاحتياج لمفردات المقرر الحالي وإجراءات تتفيذه ومصادر التعلم الخاصة به" والقبول بالفرضية

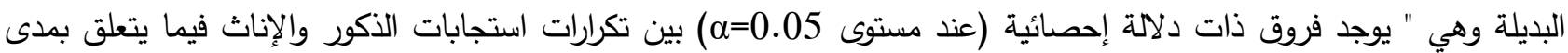
الاحتياج لمفردات المقرر الحالي وإجراءات تتفيذه ومصادر التعلم الخاصة به"، هذا يشير إلى وجود اختلافات ذات دلالة معنوية في استجابة عينة الدراسة من الطلاب والطالبات لكل فقرة، وإن الاختلافات في النسب الخاصة بالعينة عي نفسها الخات الخاصة بالمجتمع، مما يعنى إمكانية تعميم نتائج الدراسة على مجتمع الدراسة. 


\section{في ضوء نتائج الدراسة، فإنها توصي بما يأتي:}

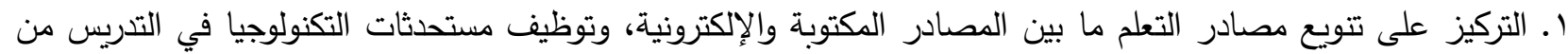

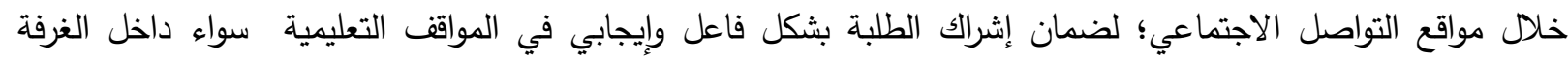

$$
\text { الصفية أم خارجها. }
$$

r. إجراء تعديل في الخطة الدراسية لطلاب كلية التربية في جامعة الملك فيصل، بحيث يُقدّم مقرر بناء وتطوير المناهج ابتداءً

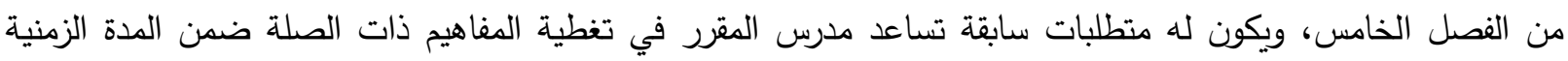

$$
\text { المتاحة خلال الفصل الدراسي. }
$$

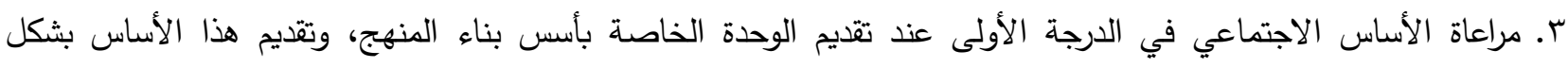
وظيفي، بحيث يتم عرض قضايا ومشكلات حقيقية تواجه المجتمع بكافة أفراده ومؤسساته، وتدريب الطلبة التاهي على كيفية تضمينها في المناهج الدراسية. ع. إدراج تجربة المملكة العربية السعودية في مجال بناء الدناهج الدراسية المطورة كموضوع رئيس في المقرر، واستعراض

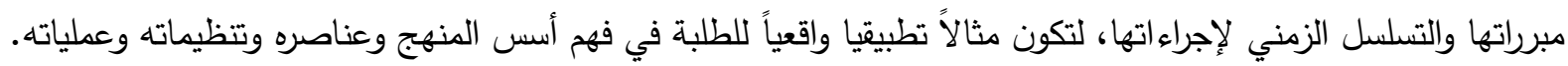

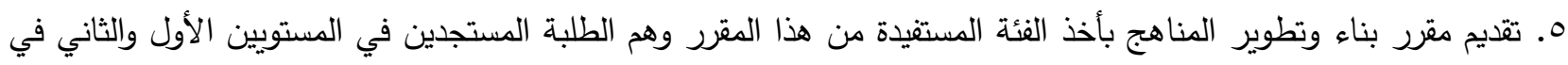

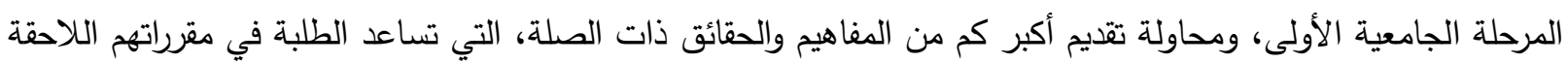

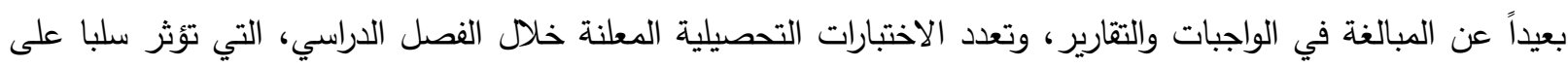

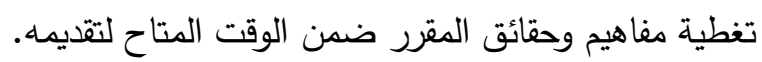

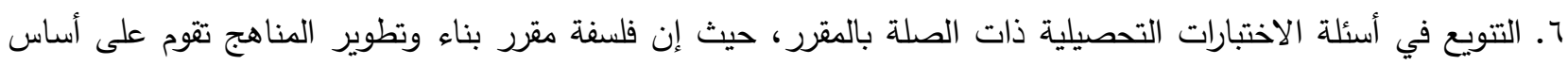

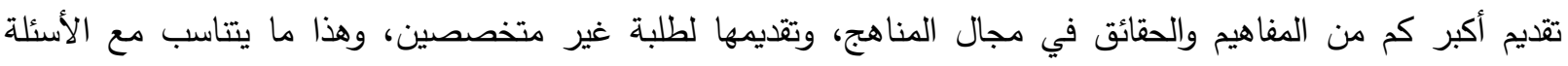
الموضوعية المقننة والأسئلة الدقالية القصيرة. V. تقليل أعداد الطلبة في الصف الدراسي بحيث لا يتجاوز الثلاثين، بما يتيح الفرصة لأساتذة المقرر لتطبيق الأنثطة المتتوعة

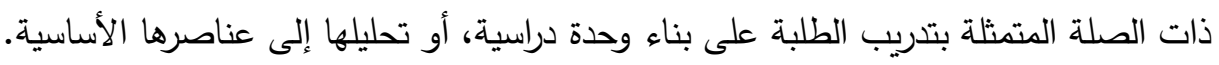

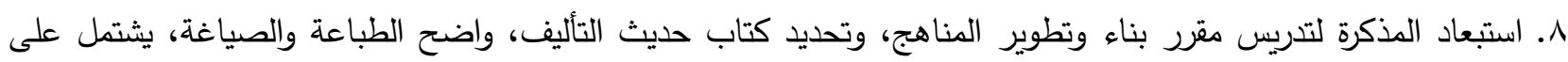
جميع مفردات العقرر المعتمة من قسم المناهج وطرق التدريس في التوصيف الذي يعده أستاتذة المقرر، إضافة إلى تحديد بعض مصادر التعلم الالكتروني التي تثري تعلم الطلبة في مجال المناهج الدراسية.

ا ـ أبو عقيل، ابراهيم ابراهيم (ع (ب). استراتيجية تعديل وتطوير الخطط الدراسية للمناهج التربوية الجامعية في الجامعات

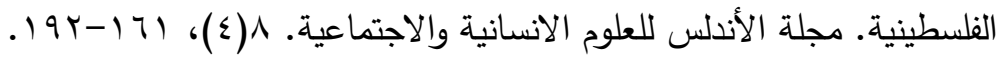

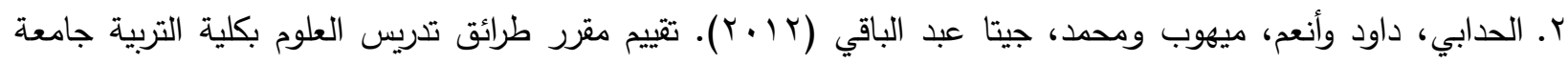

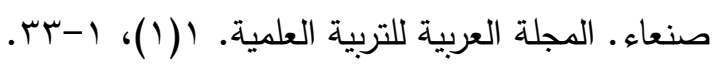

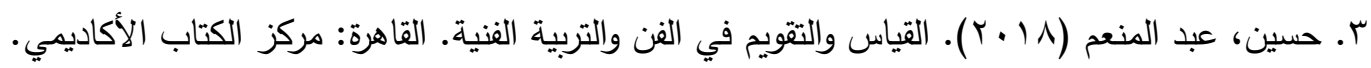

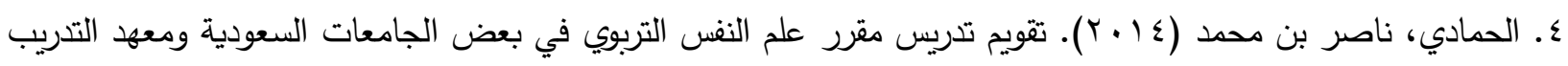
الأمني. مجلة التربية (جامعة الأزهر). 
ه. الخضيري، صالح بن عبدالله (r . . r). تقويم مقرر أدب الأطفال في أقسام اللغة العربية بكليات المعلمين. رسالة الخليج

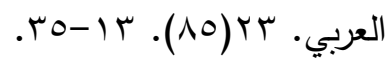

7. الشهراني، مسعود محمد (1) • (1). تقويم مقرر جغرافية المملكة العربية السعودية بكليات المعلمين في ضوه أهدافه من

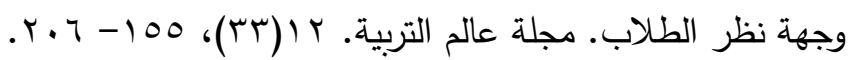

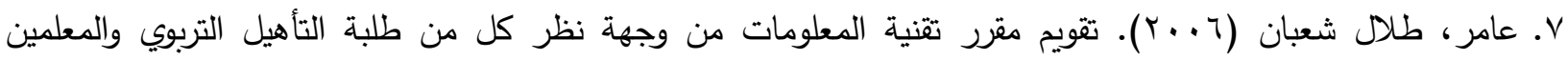
العمانيين. ورقة علمية مقدمة إلى المؤتمر العلمي الثاني للجمعية العربية لتكنولوجيا التربية المعلوماتية ومنظومة منية

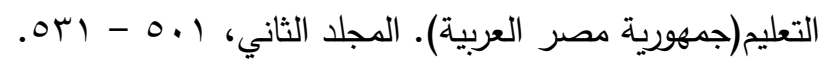

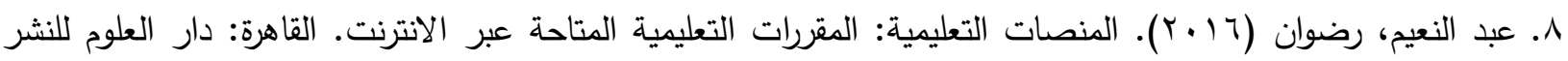
والتوزيع.

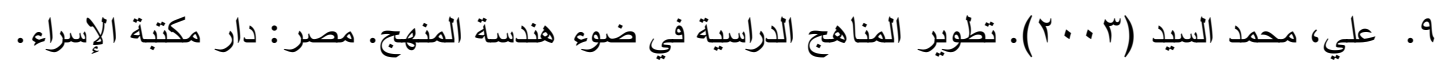

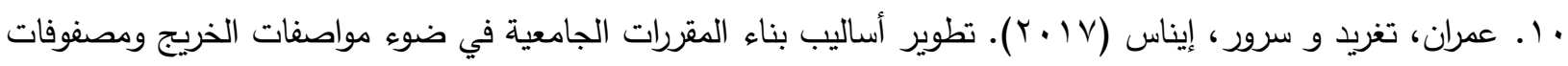

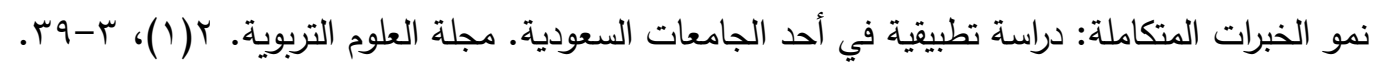

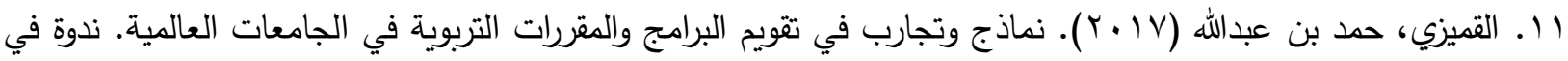

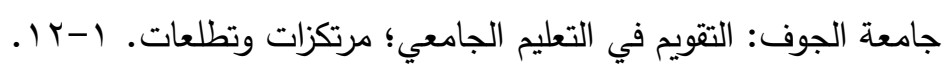

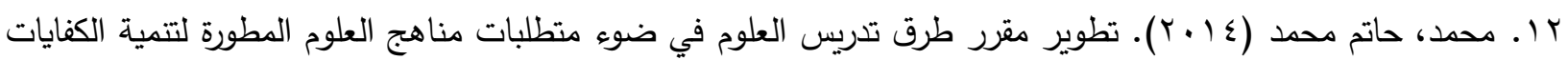

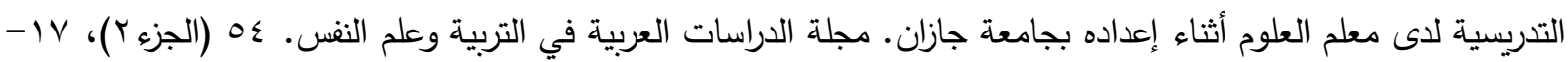
$.0 \leqslant$ ثانياً: المراجع الأجنبية:

[1] E. Akdemir , E. N. Karames \& A. Arslan, (2015). Descriptive Analysis of Researches on Curriculum Development in Education. Procedia-Social and Behavioral Sciences, 174: 3199- 3203.

[2] J. J.Forest \& P. Altbach, (2007). International Handbook in Higher Education. Part1: Global Themes and Contemporary Challenges. Netherland: Springer.

[3] A. V.Kelly, (2004). The Curriculum: Theory and Practice. London: SAGE Publications Limited.

[4] A., K. Parashar \& R. Parashar, (2012). Innovations and Curriculum Development for Engineering Education and Research in India. Procedia-Social and Behavioral Sciences, 56: $685-690$.

[5] S. F. Shawer, (2017). Teacher-Driven curriculum Development at the Classroom Level: Implications for Curriculum, Pedagogy and Teacher Training. Teaching and Teacher Education, 63: 296-313.

[6] L.Tanner \& D. Tanner, (2007). Curriculum Development: Theory into Practice. New Jersey: Prentice Hall.

[7] J. Wiles, (2009). Leading curriculum Development. California: Crown Press, A SAGE Company. 


\title{
The Requirements to Develop Curriculum Construction Course form the Point of Views of the Students and Teaching Staff in the King Faisal University
}

\author{
Mohannad A. Aljafary \\ Assistant Professor at Department of Curriculum and Teaching Methods \\ King Faisal University- Saudi Arabia \\ aljafary@kfu.edu.sa
}

\section{Shaher R. Elayyan}

Assistant Professor at Faculty of Education and Arts

Sohar University- Sultanate of Oman

se72sc@gmail.com

\begin{abstract}
:
The current study falls in line with the contemporary effort aiming towards developing teaching and learning system in King Faisal University in Saudi Arabia. It aims to investigate the requirements necessary to develop Curriculum Construction course for the students in The Faculty of Education. The descriptive survey approach was adopted in the methodology of the study, and the questionnaire which included 60 items as its tool which were distributed to three fields: course's items, teaching procedures and learning resources. The study sample consisted of (20) related teaching staff and students (75 male and 58 female) that choosing randomly. Study findings showed the importance of some items to teach this course such as: the relationship between the curriculum and the society issues, and study the Saudi Arabia experiment in the field of the development curriculum. The findings also emphasized the importance of some procedures during teaching the course such as: diversification between questions in the achievement tests, existing a suitable number of students in each section and neglecting the academic abstracts and summations as the learning resources.
\end{abstract}

Keywords: Curriculum construction and development, Curriculum development. 